\title{
LOS MOLUSCOS FLUVIALES EN LA SUBSISTENCIA DE LOS GRUPOS CAZADORES-RECOLECTORES DEL HUMEDAL DEL PARANÁ INFERIOR.
}

\section{THE FLUVIAL MOLLUSKS IN THE SUBSISTENCE OF THE HUNTER- GATHERERS OF THE LOWER PARANÁ WETLAND.}

Daniel Loponte ${ }^{1}$, Florencia Parisi ${ }^{2}$, Jorge Liotta ${ }^{3}$, Mario Wagner ${ }^{4}$ y Alejandro Acosta ${ }^{5}$

${ }^{1}$ Consejo Nacional de Investigaciones Científicas y Técnicas. Instituto Nacional de Antropología y Pensamiento Latinoamericano. 3 de febrero 1378 (C1426BJN), Ciudad de Buenos Aires. daniel.loponte@inapl.gob.ar

2Instituto Nacional de Antropología y Pensamiento Latinoamericano. 3 de febrero 1378

(C1426BJN), Ciudad de Buenos Aires. flosipar@gmail.com

${ }^{3}$ Museo de Ciencias Naturales Antonio Scasso, San Nicolás, Buenos Aires. 3 de febrero 1378 (C1426BJN), Ciudad de Buenos Aires. jorgerliotta@gmail.com

${ }^{4}$ Consejo Nacional de Investigaciones Científicas y Técnicas. Instituto Nacional de Antropología y Pensamiento Latinoamericano. 3 de febrero 1378 (C1426BJN), Ciudad de Buenos Aires. visitas@museoscasso.com.ar

${ }^{5}$ Consejo Nacional de Investigaciones Científicas y Técnicas. Instituto Nacional de Antropología y Pensamiento Latinoamericano. 3 de febrero 1378 (C1426BJN), Ciudad de Buenos Aires. acostaalejandro@gmail.com

Presentado: 30/11/2018 - Aceptado: 10/03/2019

\section{Resumen}

En este trabajo se discute el rol de los moluscos fluviales en la subsistencia de los grupos cazadores-recolectores del tramo final de la cuenca del río Paraná, especialmente de Diplodon (Rhipidodonta) variabilis. Se analiza su disponibilidad ambiental, la distribución de tallas en un banco actual y las relaciones alométricas entre los pesos del tejido blando y del exoesqueleto. Paralelamente, se describe la posición de este bivalvo dentro del ranking de las presas locales, y su incorporación en el proceso regional de diversificación e intensificación de la subsistencia durante el Holoceno tardío. Luego, con los resultados obtenidos, se analizan los conjuntos arqueomalacológicos recuperados en los sitios Punta Canal (900 \pm 80 años ${ }^{14} \mathrm{C}$ AP), La Bellaca sitio 1 (1110 \pm 70 años ${ }^{14} \mathrm{C}$ AP) y Cerro Lutz $\left(730 \pm 70 / 953 \pm 47\right.$ años ${ }^{14} \mathrm{C}$ AP), donde se discuten las actividades de recolección, la selectividad dimensional y el aporte neto de alimento. Finalmente, se analizan las señales isotópicas transferidas a los humanos relacionados con la ingesta de esta especie.

Palabras claves: Diplodon (Rhipidodonta) variabilis, río Paraná, consumo de moluscos, alometría, isótopos estables. 


\begin{abstract}
This paper discusses the role of fluvial mollusks in the subsistence of the hunter-gatherer groups of the Lower Parana basin, especially the bivalve Diplodon (Rhipidodonta) variabilis. Their environmental availability, the distribution of sizes in a colony and the allometric relationships between the weights of the soft tissue and the exoskeleton are analyzed. In parallel, the position of this bivalve in the ranking of local prey and their incorporation into the regional process of diversification and intensification of subsistence are analyzed. Based on the results obtained, the archeomalacological assemblages recovered at Punta Canal sites (900 \pm 80 years $\left.{ }^{14} \mathrm{C} \mathrm{BP}\right)$, La Bellaca site 1 (1110 \pm 70 years $\left.{ }^{14} \mathrm{C} \mathrm{BP}\right)$ and Cerro Lutz (730 $\pm 70 / 953 \pm 47{ }^{14} \mathrm{C}$ BP years) are discussed. Finally, the isotopic signals transferred to humans related to the intake of this species are analyzed.
\end{abstract}

Keywords: Diplodon (Rhipidodonta) variabilis, Paraná River, mollusks consumption, allometry, estable isotopes.

\title{
Introducción
}

El consumo sistemático de moluscos entre los cazadores-recolectores es habitual en aquellos grupos cuyos nichos efectivos están diversificados, y que de manera frecuente y concurrente, incluyen conductas de intensificación. Esta diversificación se entiende como un número sustantivo de recursos explotados, que impacta en una mayor amplitud de la dieta, mientras que la intensificación comprende, entre otros aspectos, la incorporación de recursos de mediano y bajo ranking. Estos últimos son, precisamente, indicadores del decrecimiento del rendimiento neto de las actividades de subsistencia (Binford 2001, Stephens y Krebs 1986, Munro y Atici 2009, Stinner y Munro 2002, Stiner et al. 2000). No obstante esta regla general, las mujeres y los niños pueden incorporar recursos de bajo ranking que no necesariamente denotan un decrecimiento en los retornos netos globales. En uno y otro caso, esta cooperación sexo-etaria en la obtención de alimentos sucede habitualmente en aquellos paisajes donde existen recursos que son de fácil obtención, que tienen costos de recolección acotados, y que incumben un bajo riesgo personal. Un ejemplo clásico al respecto es la explotación de moluscos, tanto en la cuenca del Paraná como en otras regiones del mundo (Arenas 2003, Bird y Bliege Bird 1997, 2000, Codding et al. 2014; Meehan 1982, Moss 1993).

En el humedal del Paraná inferior, la diversificación en la subsistencia y el desarrollo de prácticas de intensificación ya se observan en los registros del III mileno $\mathrm{AP}$, que corresponden a los sitios Playa Mansa e Isla Lechiguanas 1 nivel IV (Acosta et al. 2010, Loponte et al. 2012). Parte de esta diversificación e intensificación corresponde a la explotación de moluscos correspondientes a la especie Diplodon (Rhipidodonta) variabilis ${ }^{1}$. A partir de aquí, estos invertebrados están presentes en prácticamente todos los sitios arqueológicos en cantidades variables, inclusive formando concheros. En este trabajo exploraremos algunas líneas metodológicas para el análisis de los conjuntos malacológicos de la región y su aplicación respectiva en tres conjuntos arqueológicos del área (Figura 1). Para ello, en la primera parte de este estudio analizamos la composición de un banco natural de $D$. (R.) variabilis, las relaciones alométricas que 
existen entre las partes blandas y duras de esta especie ${ }^{2}$, su disponibilidad ambiental y la relación que guarda en términos de jerarquía con otros recursos seleccionados por los cazadores-recolectores del área. Luego, utilizamos estos resultados para discutir la composición de los conjuntos malacológicos de los sitios Punta Canal, La Bellaca sitio 1 y Cerro Lutz. Finalmente, concluimos esta presentación con un análisis destinado a precisar cuáles fueron las señales isotópicas transferidas a los humanos debido al consumo de esta especie.
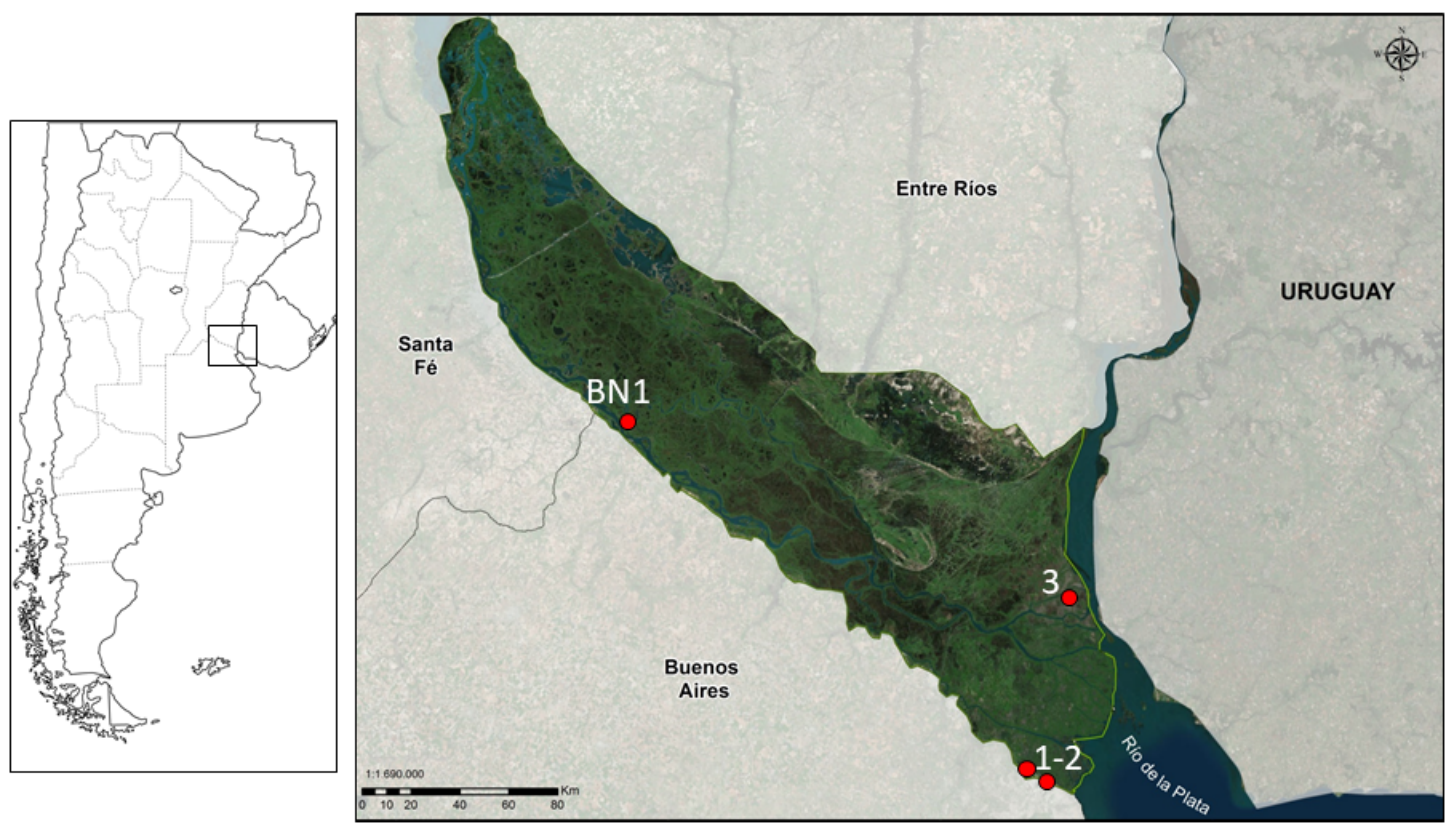

Figura 1. Área de estudio con ubicación de los sitios analizados en este trabajo. 1. Punta Canal. 2: La Bellaca sitio 1.3: Cerro Lutz. BN1: banco natural de D. (R.) variabilis.

\section{Aspectos eto-ecológicos y explotación de D. (R.) variabilis}

El género Diplodon corresponde a la familia Hyriidae que es endémica de la Región Neotropical, y que está ampliamente distribuida en la cuenca del Paraná (Torres et al. 2013). Son organismos filtradores bentónicos que prefieren sustratos blandos, limosos y secundariamente arenosos, poco compactados. D. (R.) variabilis selecciona preferentemente cuerpos de agua permanentes, tanto en ambientes lóticos como lénticos con alguna escorrentía; raramente se encuentran en aguas estancadas o pajonales inundables, donde por el contrario, son más frecuentes algunas especies de gasterópodos. Este molusco, que alcanza $10 \mathrm{~cm}$ de longitud, posee valvas de diseño discoide - elipsoide con una ligera inequilateralidad, las cuales del lado externo presentan líneas de crecimiento esculpidas de manera concéntrica y de diseño característico. Los bordes anteroventrales presentan cierta variabilidad que incluye tanto diseños robustos como más gráciles, constituyendo dos morfotipos. Posee charnelas heterodontas que también presentan claves anatómicas distintivas y de manera concurrente con la variabilidad anterior, dos morfotipos de dientes pseudocardinales, uno más robusto y otro más grácil y alargado con formas intermedias, y que serían parte de la variabilidad fenotípica de D. (R.) variabilis. 
Finalmente, del lado interno de los exoesqueletos se encuentran las cavidades de inserción de los músculos aductores, con diseños típicos para el contexto malacológico local. Todas estas características morfológicas facilitan las determinaciones específicas tanto de las charnelas como de los fragmentos de los exoesqueletos esta especie.

En términos de su oferta ambiental, $D$. (R.) variabilis forma bancos de cientos e incluso miles de individuos, con patrones de desagregación y agregación no bien comprendidos. Estos bancos presentan picos de densidad con espacios intermedios sin que se registren individuos, a veces de cientos de metros. Los bancos pueden permanecer fijos durante un tiempo y luego trasladarse, desconociéndose las frecuencias y las distancias de estos movimientos (Bonetto 1961, Bonetto et al. 1950, 1973, Castellanos 1960, 1965). Los muestreos efectuados sobre bancos contemporáneos muestran que son agrupaciones monoespecíficas, pero también pueden incluir cantidades pequeñas de Diplodon parallelopipedon, lo cual ayuda a explicar la baja presencia de esta especie en los conjuntos arqueológicos dominados por $D$. (R.) variabilis (Caggiano 1984, Loponte 2008, Parisi y Liotta 2010, ver algunas posibles excepciones, por ejemplo, en Torres 1911, quien describe grandes acumulaciones de $D$. parallelopipedon en el sitio Cementerio I del Paraná Guazú, como así también comentarios respecto a su disponibilidad ambiental en Chiri 1972).

Hoy en día D. (R.) variabilis se obtiene con diferentes métodos, según el nivel de las aguas y el grado de intensidad aplicada por el recolector. El proceso comienza con la remoción del fondo de los arroyos o lagunas con las manos, los pies o un palo; los ejemplares liberados del sustrato son tomados con la mano, lo que implica cierta selectividad dimensional. Otra técnica de remoción incluye el uso de un "rastrillo almejero", que tiene una red adosada. El rastrillo se hunde ligeramente en el sustrato y se arrastra a lo largo del fondo, ayudado generalmente con la fuerza de un bote a motor, quedando los moluscos retenidos en una red sujeta en el lado posterior del rastrillo. La recolección efectuada de esta manera es dimensionalmente indiscriminada, dependiendo de la composición del banco, del tamaño del tejido de la red, y de la eventual selectividad posterior del operador. El empleo de redes es señalada para un sector impreciso de la cuenca del Paraná, como la forma de recolección de este recurso por parte de los grupos aborígenes en el siglo XVI, pero no se describe el método de remoción de las valvas del sustrato (del Barco Centenera 1900:23).

Para los grupos humanos que tuvieron una movilidad residencial reducida como los cazadores-recolectores del curso medio e inferior del río Paraná, los moluscos poseen múltiples propiedades atractivas para su explotación. Son relativamente predecibles en el tiempo y en el espacio. Pueden ser recolectados en el momento que se considere oportuno y sus bancos poseen una significativa capacidad de resiliencia. Su obtención incumbe un bajo riesgo personal y el equipo necesario para su obtención es de bajo costo de manufactura y manutención. Diferentes categorías sexo-etarias de los grupos humanos pueden obtenerlos 
fácilmente, incorporando los bancos dentro de los circuitos diarios de abastecimiento. Una vez recolectados, se conservan algunos días dentro de sus valvas y aún más en un medio acuoso, por lo tanto se puede diferir su consumo. Todas estas características, además de incentivar su incorporación a la dieta, pudieron haber estimulado el desarrollo de conductas de apropiación de los parches de recolección, y eventualmente, incentivar estrategias de conservación del recurso (cf. Alvard 1995, 2003, Bunyard 1989, Codding et al. 2014, Harris 1979).

\section{Relaciones alométricas de D. (R.) variabilis}

Uno de los mayores problemas de la zooarqueología es calcular cuánta biomasa estuvo disponible considerando los restos faunísticos recuperados. En las valvas este problema es clásico debido a la fragmentación, lo cual deriva en la dificultad para cuantificar la cantidad de individuos presentes (ver diferentes posturas en Claassen 1998, 2000, Giovas 2009, Mason et al. 1998, Peacock 2000). El registro malacológico, además, incumbe habitualmente millares de especímenes de pequeño tamaño, por lo cual los valores de NISP se tornan relativos para compararlos con otros recursos, generando a menudo problemas metodológicos que tornan impracticable un adecuado cálculo del MNI debido a la fragmentación. Una solución para ello, especialmente para conjuntos muy fragmentados, es obtener ecuaciones alométricas que relacionen los pesos de las valvas con las proporciones edibles de cada especie. Para nuestro caso de estudio, se muestreó un banco natural (BN1) de D. (R.) variabilis ubicado el sector septentrional de la Isla Lechiguanas (provincia de Entre Ríos), muy próximo a la margen izquierda del río Paraná, frente a la localidad bonaerense de Villa Constitución (Figura 1). La recolección se efectuó con un rastrillo "almejero" y una red adosada. Los ejemplares así obtenidos se midieron y se pesaron. Luego se extrajo el tejido blando y se pesó de manera separada de su exoesqueleto. De esta manera se obtuvo la distribución de tallas que nos permite conocer cómo se presenta parte de la oferta natural de esta especie, cuál es la proporción de tejido blando y duro y qué las relaciones alométricas guardan estas partes constitutivas (Tabla 1 y Figura 2).

Según los resultados obtenidos en la Tabla 1 , el tejido edible de $D$. (R.) variabilis representa 25,6 6 3,5\% del peso del ejemplar vivo. Este valor tiene un coeficiente de variación relativamente bajo $(13,6 \%)$, que es aún más pequeño para los juveniles y mayor en los adultos, reflejo de las distintas trayectorias metabólicas a lo largo de la vida de los individuos adultos. En los ejemplares de más de 80 gr de peso total, la fracción blanda de un ejemplar vivo disminuye a $22,4 \pm 4,2 \%$, producto de la mayor robustez de la estructura umbonal y del mayor grosor de los exoesqueletos. La ecuación alométrica obtenida en la Figura $2.1\left(\mathrm{y}=0.2155 \mathrm{x}+0.5767 ; \mathrm{r}_{\mathrm{s}} 0,98, \mathrm{p}>\right.$ 0.001) también puede ser empleada para estimar la cantidad de alimento a partir del peso bruto del individuo vivo, reemplazando el valor de " $\mathrm{x}$ " por el peso vivo de los ejemplares. 

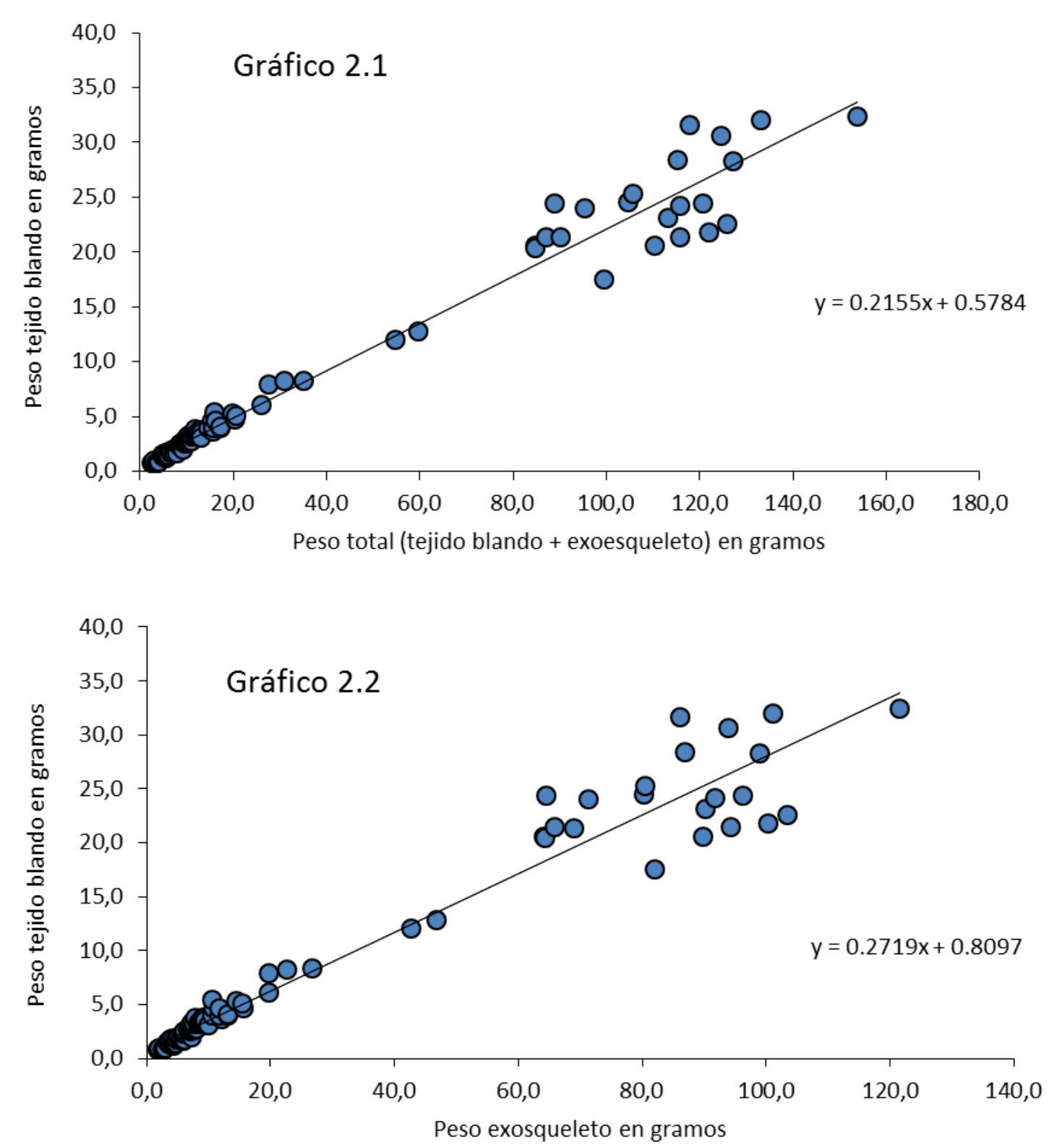

Figura 2. Gráfico 2.1: regresión y coeficiente de determinación entre el peso vivo de los individuos (tejido blando + exoesqueleto) y del tejido blando de $D$. (R.) variabilis en BN1. Gráfico 2.2: regresión y coeficiente de determinación entre el peso del exoesqueleto y del tejido blando de D. (R.) variabilis en BN1.

Para obtener la fracción consumible presente en una colección arqueológica a partir del peso de los exoesqueletos, la ecuación alométrica surge del gráfico 2.2 (y = $\left.0,2719 x+0,8097 ; r_{s} 0,97, p>0.001\right)$. Para aplicarla hay que reemplazar " $x$ " por el peso de los exoesqueletos recuperados del contexto arqueológico. Otra aproximación alternativa para estimar la biomasa útil es calcular el 34,6\% del peso de los exoesqueletos, dado que este es el porcentaje que corresponde al peso del tejido blando asociado (ver Tabla 1). Este porcentaje disminuye a $\sim 29 \%$ en el caso de los individuos mayores a 80 gramos de peso vivo. 


\begin{tabular}{|c|c|c|c|c|c|c|c|c|c|c|c|}
\hline 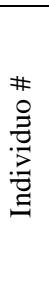 & 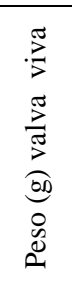 & 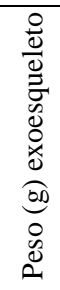 & 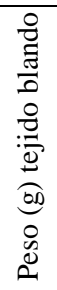 & 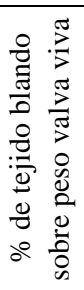 & 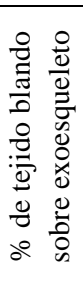 & 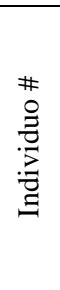 & 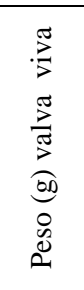 & $\begin{array}{l}\frac{0}{0} \\
\frac{0}{0} \\
\tilde{\Xi} \\
0 \\
0 \\
0 \\
0 \\
00 \\
0 \\
0 \\
0 \\
0\end{array}$ & 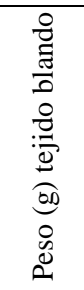 & 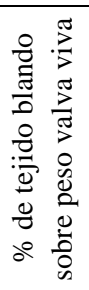 & $\begin{array}{ll}0 & 0 \\
0 & \frac{0}{0} \\
\frac{0}{0} & 0 \\
0 & 0 \\
0 & 0 \\
: 0 & 0 \\
0 & 0 \\
0 & 0 \\
0 & 0 \\
0 & 0 \\
0 & 0\end{array}$ \\
\hline 1 & 2.6 & 1.8 & 0.8 & 30.8 & 44.4 & 50 & 12.5 & 9.1 & 3.4 & 27.2 & 37.4 \\
\hline 2 & 2.7 & 1.9 & 0.8 & 29.6 & 42.1 & 51 & 12.6 & 9.4 & 3.2 & 25.4 & 34.0 \\
\hline 3 & 3.1 & 2.1 & 1.0 & 32.3 & 47.6 & 52 & 12.7 & 9.0 & 3.7 & 29.1 & 41.1 \\
\hline 4 & 3.5 & 2.7 & 0.8 & 22.9 & 29.6 & 53 & 12.7 & 9.6 & 3.1 & 24.4 & 32.3 \\
\hline 5 & 3.7 & 2.9 & 0.8 & 21.6 & 27.6 & 54 & 12.8 & 9.6 & 3.2 & 25.0 & 33.3 \\
\hline 6 & 3.9 & 3.0 & 0.9 & 23.1 & 30.0 & 55 & 12.9 & 9.2 & 3.7 & 28.7 & 40.2 \\
\hline 7 & 4.8 & 3.3 & 1.5 & 31.3 & 45.5 & 56 & 13.0 & 9.5 & 3.5 & 26.9 & 36.8 \\
\hline 8 & 4.9 & 3.5 & 1.4 & 28.6 & 40.0 & 57 & 13.2 & 10.1 & 3.1 & 23.5 & 30.7 \\
\hline 9 & 5.1 & 3.8 & 1.3 & 25.5 & 34.2 & 58 & 14.6 & 10.6 & 4.0 & 27.4 & 37.7 \\
\hline 10 & 5.4 & 4.1 & 1.3 & 24.1 & 31.7 & 59 & 15.3 & 10.7 & 4.6 & 30.1 & 43.0 \\
\hline 11 & 5.4 & 3.7 & 1.7 & 31.5 & 45.9 & 60 & 15.7 & 12.1 & 3.6 & 22.9 & 29.8 \\
\hline 12 & 5.6 & 4.4 & 1.2 & 21.4 & 27.3 & 61 & 15.7 & 11.7 & 4.0 & 25.5 & 34.2 \\
\hline 13 & 5.7 & 4.4 & 1.3 & 22.8 & 29.5 & 62 & 16.0 & 10.6 & 5.4 & 33.8 & 50.9 \\
\hline 14 & 5.8 & 4.4 & 1.4 & 24.1 & 31.8 & 63 & 16.3 & 11.7 & 4.6 & 28.2 & 39.3 \\
\hline 15 & 6.0 & 4.2 & 1.8 & 30.0 & 42.9 & 64 & 17.1 & 13.1 & 4.0 & 23.4 & 30.5 \\
\hline 16 & 6.0 & 4.6 & 1.4 & 23.3 & 30.4 & 65 & 17.3 & 13.2 & 4.1 & 23.7 & 31.1 \\
\hline 17 & 6.2 & 4.6 & 1.6 & 25.8 & 34.8 & 66 & 19.7 & 14.4 & 5.3 & 26.9 & 36.8 \\
\hline 18 & 6.2 & 4.8 & 1.4 & 22.6 & 29.2 & 67 & 20.4 & 15.7 & 4.7 & 23.0 & 29.9 \\
\hline 19 & 6.6 & 4.9 & 1.7 & 25.8 & 34.7 & 68 & 20.6 & 15.5 & 5.1 & 24.8 & 32.9 \\
\hline 20 & 6.7 & 4.8 & 1.9 & 28.4 & 39.6 & 69 & 25.9 & 19.8 & 6.1 & 23.6 & 30.8 \\
\hline 21 & 7.1 & 5.1 & 2.0 & 28.2 & 39.2 & 70 & 27.6 & 19.7 & 7.9 & 28.6 & 40.1 \\
\hline 22 & 7.4 & 5.6 & 1.8 & 24.3 & 32.1 & 71 & 30.9 & 22.7 & 8.2 & 26.5 & 36.1 \\
\hline 23 & 7.5 & 5.9 & 1.6 & 21.3 & 27.1 & 72 & 35.1 & 26.8 & 8.3 & 23.6 & 31.0 \\
\hline 24 & 7.8 & 6.1 & 1.7 & 21.8 & 27.9 & 73 & 54.7 & 42.7 & 12.0 & 21.9 & 28.1 \\
\hline 25 & 8.3 & 5.9 & 2.4 & 28.9 & 40.7 & 74 & 59.6 & 46.8 & 12.8 & 21.5 & 27.4 \\
\hline 26 & 8.3 & 6.0 & 2.3 & 27.7 & 38.3 & 75 & 84.7 & 64.1 & 20.6 & 24.3 & 32.1 \\
\hline 27 & 8.6 & 6.1 & 2.5 & 29.1 & 41.0 & 76 & 84.8 & 64.4 & 20.4 & 24.1 & 31.7 \\
\hline 28 & 8.6 & 6.1 & 2.5 & 29.1 & 41.0 & 77 & 87.2 & 65.8 & 21.4 & 24.5 & 32.5 \\
\hline 29 & 9.2 & 6.9 & 2.3 & 25.0 & 33.3 & 78 & 88.9 & 64.5 & 24.4 & 27.4 & 37.8 \\
\hline 30 & 9.2 & 7.2 & 2.0 & 21.7 & 27.8 & 79 & 90.2 & 68.9 & 21.3 & 23.6 & 30.9 \\
\hline 31 & 9.3 & 6.7 & 2.6 & 28.0 & 38.8 & 80 & 95.4 & 71.4 & 24.0 & 25.2 & 33.6 \\
\hline 32 & 9.6 & 7.1 & 2.5 & 26.0 & 35.2 & 81 & 99.5 & 82.0 & 17.5 & 17.6 & 21.3 \\
\hline 33 & 9.7 & 7.1 & 2.6 & 26.8 & 36.6 & 82 & 104.8 & 80.3 & 24.5 & 23.4 & 30.5 \\
\hline 34 & 9.7 & 6.8 & 2.9 & 29.9 & 42.6 & 83 & 105.8 & 80.5 & 25.3 & 23.9 & 31.4 \\
\hline 35 & 10.0 & 7.4 & 2.6 & 26.0 & 35.1 & 84 & 110.4 & 89.8 & 20.6 & 18.7 & 22.9 \\
\hline 36 & 10.1 & 7.0 & 3.1 & 30.7 & 44.3 & 85 & 113.3 & 90.2 & 23.1 & 20.4 & 25.6 \\
\hline 37 & 10.2 & 7.6 & 2.6 & 25.5 & 34.2 & 86 & 115.4 & 87.0 & 28.4 & 24.6 & 32.6 \\
\hline 38 & 10.5 & 7.5 & 3.0 & 28.6 & 40.0 & 87 & 115.7 & 94.3 & 21.4 & 18.5 & 22.7 \\
\hline 39 & 10.6 & 7.3 & 3.3 & 31.1 & 45.2 & 88 & 115.9 & 91.7 & 24.2 & 20.9 & 26.4 \\
\hline 40 & 10.6 & 7.7 & 2.9 & 27.4 & 37.7 & 89 & 117.8 & 86.2 & 31.6 & 26.8 & 36.7 \\
\hline 41 & 10.8 & 8.0 & 2.8 & 25.9 & 35.0 & 90 & 120.6 & 96.2 & 24.4 & 20.2 & 25.4 \\
\hline 42 & 10.9 & 8.1 & 2.8 & 25.7 & 34.6 & 91 & 122.1 & 100.3 & 21.8 & 17.9 & 21.7 \\
\hline 43 & 10.9 & 7.7 & 3.2 & 29.4 & 41.6 & 92 & 124.5 & 93.9 & 30.6 & 24.6 & 32.6 \\
\hline 44 & 11.4 & 8.2 & 3.2 & 28.1 & 39.0 & 93 & 126.0 & 103.4 & 22.6 & 17.9 & 21.9 \\
\hline 45 & 11.7 & 7.9 & 3.8 & 32.5 & 48.1 & 94 & 127.2 & 98.9 & 28.3 & 22.2 & 28.6 \\
\hline 46 & 11.8 & 8.5 & 3.3 & 28.0 & 38.8 & 95 & 133.2 & 101.2 & 32.0 & 24.0 & 31.6 \\
\hline 47 & 11.8 & 8.5 & 3.3 & 28.0 & 38.8 & 96 & 153.9 & 121.5 & 32.4 & 21.1 & 26.7 \\
\hline 48 & 12.0 & 8.6 & 3.4 & 28.3 & 39.5 & $\mathrm{X}$ & 34.9 & 26.8 & 8.1 & 25.6 & 34.6 \\
\hline \multirow[t]{2}{*}{49} & \multirow[t]{2}{*}{12.4} & \multirow[t]{2}{*}{8.9} & \multirow[t]{2}{*}{3.5} & \multirow[t]{2}{*}{28.2} & \multirow[t]{2}{*}{39.3} & DS & 43.1 & 33.8 & 9.4 & 3.5 & 6.3 \\
\hline & & & & & & $\mathrm{CV}$ & 123.5 & 126.3 & 116.3 & 13.6 & 18.2 \\
\hline
\end{tabular}

Tabla 1. Pesos y fracciones derivadas de $D$. (R.) variabilis en BN1. Los pesos están expresados en gramos. 


\section{Los moluscos en la diversificación e intensificación de la explotación faunística en el humedal del Paraná inferior}

Al principio de este estudio señalamos que la diversificación y la intensificación son dos conceptos centrales para comprender por qué se incorporan los moluscos, de manera sistemática y en cantidades significativas, a la dieta de los cazadoresrecolectores. Mientras que la diversificación en la explotación faunística se mide habitualmente por los índices de diversidad ${ }^{3}$ que son sensibles a la cantidad de "clases" y a la magnitud numérica de cada categoría, la intensificación se relaciona con el tipo de recursos que se incorporan a la dieta, para lo cual se utilizan criterios derivados habitualmente de los rankings de presas, la selección sexo-etaria de las mismas y las formas finales que adquiere el consumo (i.e. consumo directo, transformación, extracción de nutrientes, etc.). Los rankings de presas se basan principalmente en el retorno calórico neto que se obtiene entre la biomasa adquirida deducidos los costos y los riesgos de obtención (búsqueda, captura, cooperación, equipos necesarios, peligrosidad, etc.) (Alvard 1995, Broughton 1994, 199, Broughton et al. 2011, Stiner et al. 2000)4. Dado que varios de estos componentes no son medibles arqueológicamente, habitualmente solo se consideran los tamaños promedio de cada especie como una medida aproximada a su jerarquía relativa, sin considerar los costos asociados. Algunos autores han criticado estas aproximaciones por su simplicidad (Bird y O'Connell 2006; Jochim 1976, 1981)5, mientras que otros los consideran menos sujetos a errores y finalmente, más útiles para una aplicación arqueológica de grano grueso (Bayham 1979,; Broughton 1997, 2011, Byers et al. 2005, Hames y Vickers 1982, Hawkes et al. 1982, Hill et al. 1987, Jochim, 1998, Schmitt y Lupo 1995, Smith 1991). Esta última aproximación de carácter general, permite generar un ranking primario sencillo de elaborar para nuestra región (ver Figura 3), que es útil para aproximarse a un programa de captura basado en el tamaño de las presas. Como desventaja, es un mal predictor de la frecuencia de los taxa en el registro arqueológico, dado que no incorpora la densidad poblacional de cada especie, propiedad que incide en la tasa de encuentro con los cazadores. Por ello, algunos modelos de amplitud de dieta jerarquizan los recursos en función de las diferentes formas que adquiere la disponibilidad ambiental de los mismos (Broughton 1999, Burger et al. 2005, Byers et al. 2005, Kaplan and Hill 1992, Pyke et al. 1977, Stephens y Krebs 1986, Waguespack y Surovell 2003). La importancia de la tasa de encuentro y las formas de captura se pone de manifiesto fácilmente cuando se evalúan aquellos recursos que si bien son de tallas medianas y pequeñas, se obtienen en masa como los peces, que en nuestra región precisamente poseen el ranking más elevado. De esta manera, considerando las densidades típicas de cada especie para un ambiente dado, se puede construir un ranking secundario que incluya el peso de los individuos y la densidad poblacional.

En ambientes constituidos por mosaicos de recursos como lo es la región de estudio, la densidad poblacional conocida de las especies en cada parche debe ser promediada en función de la cobertura espacial que tiene cada unidad de paisaje. Los rankings calculados de esta manera, siguen siendo un modelo de selección de presas que no consideran la 
selección específica de los parches, pero tienen la habilidad de promediar las conductas individuales de múltiples cazadores a largo plazo, y tienen más poder explicativo para comprender el registro zooarqueológico. Mientras que es relativamente sencillo obtener esta parametrización para los mamíferos y los peces, es complejo en el caso de los moluscos, particularmente por la falta de datos respecto a la densidad de individuos en el paisaje.

En los bancos de D. (R.) variabilis, que son loci específicos dentro de los parches de agua libre, las densidades de esta especie tiene promedios de $6,1 \mathrm{i} / \mathrm{m}^{2}$, con un máximo de $69 \mathrm{i} / \mathrm{m}^{2}$, y una estimación de $1000 \mathrm{~kg} \mathrm{ha}^{-1}$ de peso bruto (Bonetto y Wais 1995; Bonetto et al. 1973). Esta última magnitud equivale a aproximadamente $216 \mathrm{~kg} \mathrm{ha}^{-1} \mathrm{de}$ tejido blando consumible, utilizando la ecuación alométrica del gráfico 2.1. (Figura 2). En BN1 se obtuvieron valores más bajos, de 0,639 i/m² y 316,3 $\mathrm{kg}^{-1} \mathrm{~m}^{-1}$ (peso bruto), lo que representa aproximadamente $68,7 \mathrm{~kg} \mathrm{ha}^{-1}$ de biomasa edible. Aquí se debe señalar que la técnica de recolección fue menos eficiente que la utilizada por Bonetto y colaboradores, y por lo tanto nuestros valores deben considerarse como magnitudes mínimas. Estos datos actualísticos parametrizados, indican una biomasa consumible que oscila entre 21.600 y $6.870 \mathrm{~kg}$ por cada $\mathrm{km}^{2}$ de aguas abiertas (es decir, un promedio de $14.235 \mathrm{~kg}$ de tejido blando por cada $\mathrm{km}^{2}$ de aguas abiertas -lagunas y arroyos-). Estos ambientes acuáticos, ocupan en la Reserva Natural Estricta de Otamendi ${ }^{6}$, tan solo 4,8 \% de la superficie total (Haene et al. 2003), mientras que en el área de $\mathrm{BN} 1$ es $12 \%$. Es decir, lo que parece ser una gran oferta de $D$. (R.) variabilis, se encuentra constreñida espacialmente a áreas relativamente pequeñas, que reducen su disponibilidad. Como una estimación que se ubica dentro del rango de variación conocido, podemos considerar que estos parches acuáticos donde se pueden obtener estos moluscos se encuentran en aproximadamente $8 \%$ de la superficie del paisaje local. Con estos datos obtenidos, tanto de pesos individuales promedio como de densidad en el espacio, se pueden incorporar a los moluscos dentro de ambos rankings de presas desarrollados para la región (Figura 3).

Como es esperable debido a su bajo peso por individuo, D. (R.) variabilis es el recurso faunístico con el menor ranking primario ${ }^{7}$, muy alejado de las otras presas explotadas, pero presenta un ranking secundario alto. De esta manera, ambos parámetros sugieren que dentro del proceso de diversificación, estos moluscos pueden haber sido ignorados o eventualmente incorporados de manera discreta, y que su consumo se habría incrementado de manera gradual o significativa concomitante con un aumento sustantivo del proceso de intensificación. 


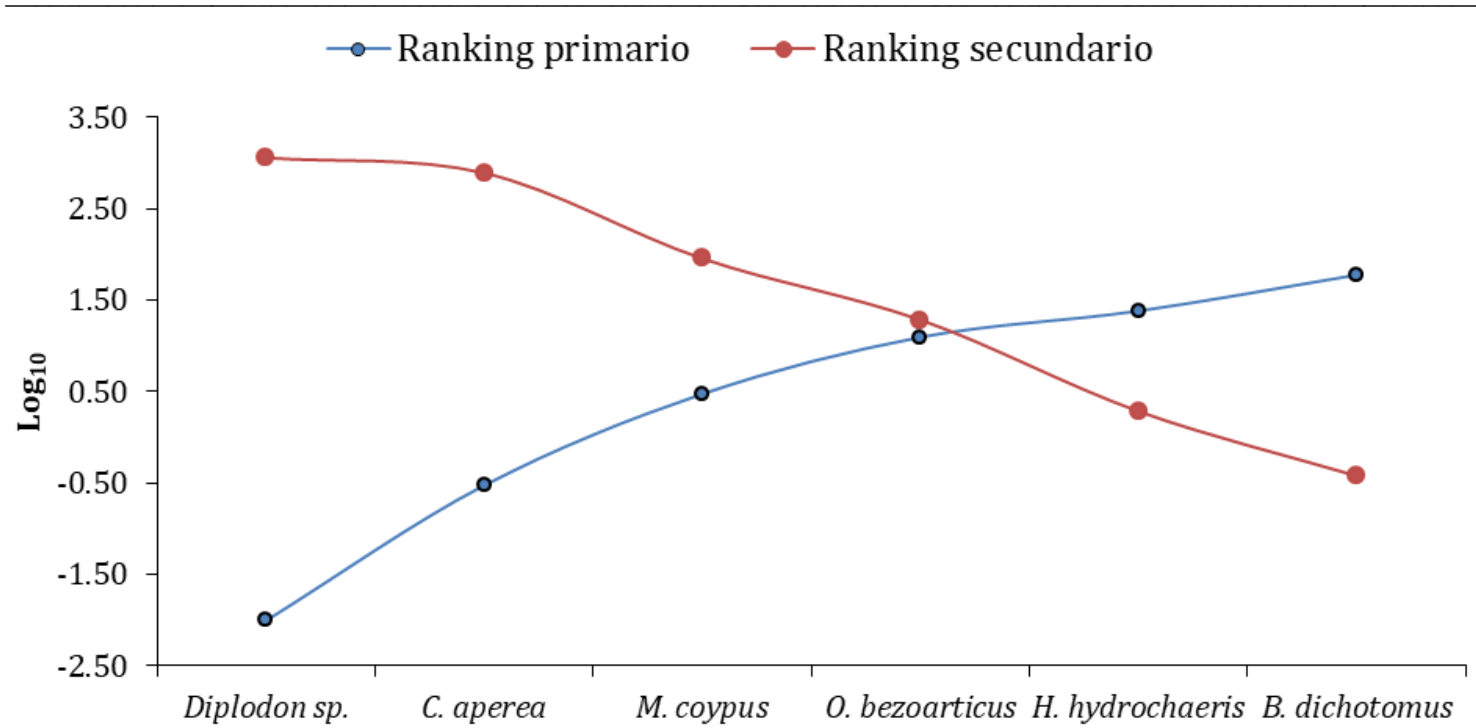

Figura 3. Rankings primarios y secundarios de las presas más frecuentes del registro arqueológico del tramo final del río Paraná inferior (tomado y modificado de Loponte 2008; el

macrotaxón peces, que es el recurso de mayor jerarquía en el ranking secundario, ha sido excluido de este gráfico). $O$. bezoarticus solo puede ser considerado como recurso presente para aquellos sitios ubicados en el ecotono de la llanura pampeana y el humedal del Paraná inferior (Loponte y Corriale 2019).

\section{Los moluscos en los contextos arqueológicos regionales}

Las valvas de $D$. (R.) variabilis son ubicuas dentro del registro arqueológico local a partir de 2400 años ${ }^{14} \mathrm{C} \mathrm{AP}$, lo que es concurrente con otras evidencias que indican que un proceso de diversificación de proporciones significativas en la obtención de alimentos ya había comenzado con anterioridad. Las cantidades presentes en cada sitio oscilan entre escasos hallazgos aislados y pequeños lentes de acumulación, hasta verdaderos concheros que muestran un proceso de intensificación. Esta variabilidad, por el momento, no parece tener un vector temporal claro, si bien falta información cuantitativa y cronológica de alcance regional sobre la presencia y cantidad de valvas en los sitios del área. En este sentido, el registro de los moluscos tiende a encontrarse descripto de manera genérica en la literatura (Caggiano 1984, González 1947, Greslebin 1931, Lothrop 1932, Torres 1911), y solo en algunos casos hay datos cuantitativos y cronológicos precisos (Loponte 2008, Loponte et al. 2016b, Liotta y Parisi 2010).

Para avanzar en este análisis, presentamos la composición de los conjuntos malacológicos de los sitios Punta Canal, La Bellaca sitio 1 y Cerro Lutz. Estos depósitos están ubicados sobre bancos fluviales o cordones de regresión, localmente conocidos como "cerros" o "albardones" que presentan una elevación ligeramente mayor que el resto del paisaje. Por ello no son tan frecuentemente sumergidos por las inundaciones periódicas que suceden en el área. La ausencia de episodios regulares de encharcamiento y un clima similar al actual, han permitido que desarrollen diferentes tipos de Molisoles, que es donde están insertos los depósitos arqueológicos (ver Figura 4). 
Los sitios y colecciones analizadas

Punta Canal representa uno o varios campamentos base o campamentos centrales ("central place foraging"; cf. Bettinger et al. 1997, Cannon 2003), expresado/s en un delgado y discreto nivel de ocupación de aproximadamente 30 cm de potencia ${ }^{8}$, fechado en $900 \pm 80$ años ${ }^{14}$ C AP (LP-2193), e inserto en un Molisol homogéneo, sin estratificación evidente. El registro faunístico y artefactual no presenta hiatos ni cambios a lo largo de la distribución arqueológica. La alfarería recuperada aquí es lisa e incisa, con un estilo tecnológico (en el sentido de Lechtman 1977) que es homogéneo a lo largo del acotado perfil del depósito, y además, entre la base y el techo del depósito arqueológico se efectuaron remontajes de fragmentos cerámicos. Por todo ello, se lo considera una unidad agregativa. Su contexto ha sido incluido dentro del informalmente denominado "Grupo de Cerámica Incisa" (GCI) (Loponte 2008). El sedimento del sitio fue removido en capas artificiales de $5 \mathrm{~cm}$ con cucharín y pincel, ligeramente cernido en seco en el sitio y traslado en bolsas al laboratorio, donde fue cernido en húmedo (ver técnica de cernido en Loponte 2008). Las valvas en este sitio se encontraban desarticuladas, la mayoría de ellas fracturadas en alto grado, sin evidencias de combustión, e íntimamente asociadas con el resto del conjunto arqueológico. Algunas de ellas han sido intervenidas para transformarlas en artefactos ornamentales (Buc et al. 2019 en este volumen).

El sitio La Bellaca 1 también es la expresión arqueológica de uno o varios campamentos base, conformado/s por una capa fértil de $60 \mathrm{~cm}$ de potencia, que en algunos sectores desciende a $40 \mathrm{~cm}$, extinguiéndose progresivamente hacia la periferia del albardón. Un fechado del sector medio del depósito arrojó una antigüedad de 1110 \pm 70 años ${ }^{14} \mathrm{C}$ AP (LP-1288). Su alfarería es diferente a la recuperada en Punta Canal, ya que es completamente lisa y posee una terminación más rudimentaria. Este contexto ha sido incluido dentro del (también informalmente denominado) "Grupo de Cerámica Lisa" (GCL), el cual presenta diferencias en varios componentes tecnológicos, simbólicos y de subsistencia respecto al anterior (Loponte 2008). Internamente, la alfarería de La Bellaca 1 es tecno-estilísticamente homogénea a lo largo del perfil del sitio, con remontajes positivos entre los diferentes niveles artificiales de extracción. El registro faunístico y artefactual no presenta variaciones sustantivas a lo largo del perfil, como así tampoco el Molisol que es homogéneo y sin estratificación. Por todo ello se lo considera una unidad agregativa. El sedimento del sitio fue removido en capas artificiales de $5 \mathrm{~cm}$ con cucharín y pincel; una parte del mismo fue cernido en seco y una fracción con cernido en húmedo. Las valvas recuperadas se presentaban desarticuladas, sin evidencias de combustión, distribuidas de manera dispersa y concurrente con el resto del conjunto arqueológico. Se identificaron algunos lentes de valvas más densos en los sectores periféricos del sitio que podrían corresponder a áreas específicas de descarte. Algunas valvas también fueron utilizadas para confeccionar artefactos ornamentales (Loponte 2008 y Buc et al. 2019 en este volumen). 

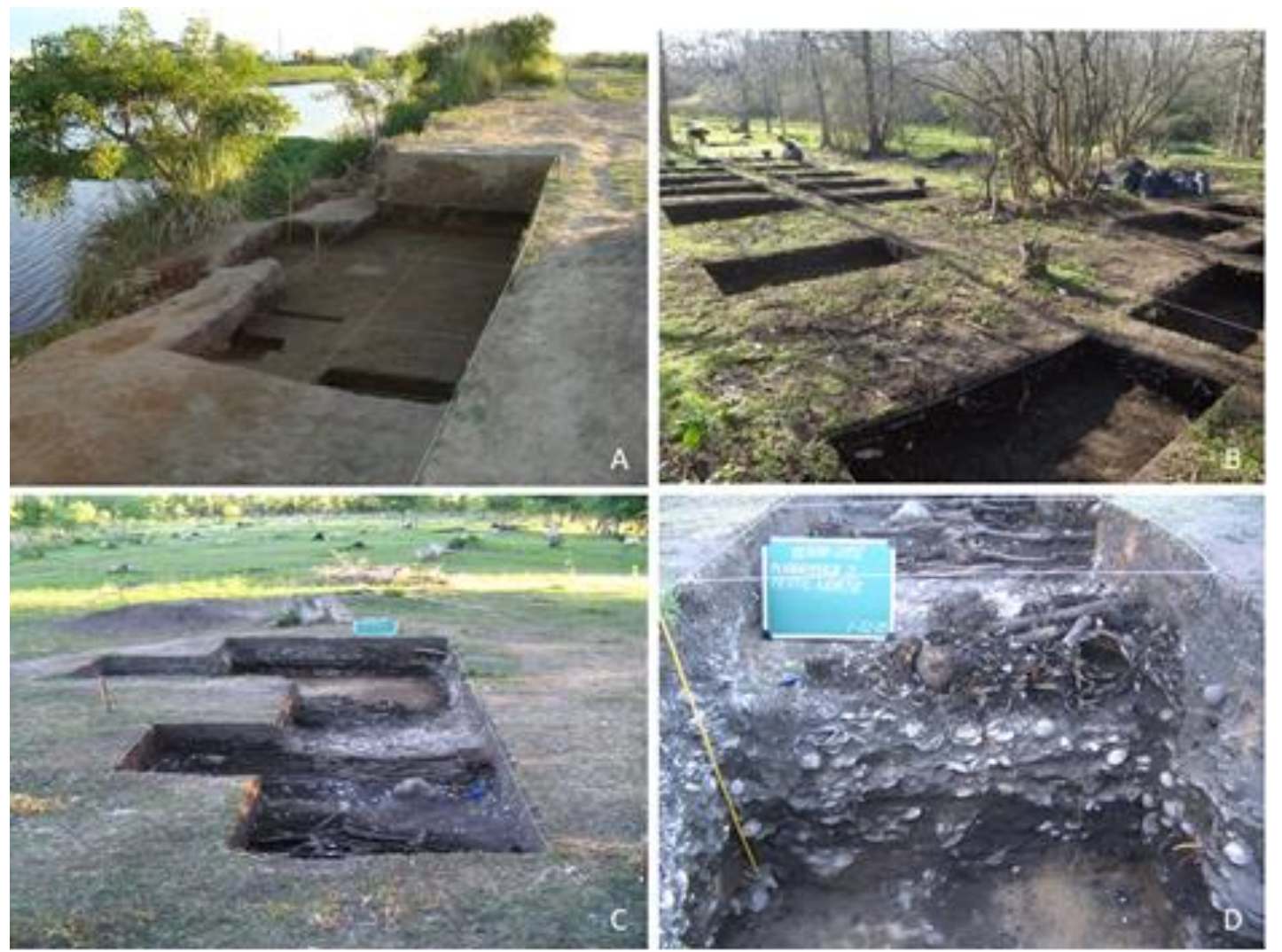

Figura 4. Vista general de las áreas de excavación de los sitios analizados en este trabajo. A: Punta Canal. B: La Bellaca sitio 1. C: Cerro Lutz. D: Detalle de un sector del perfil de Cerro Lutz, con exposición del conchero y una estructura de inhumación en el ángulo superior derecho, excavada en el techo del mismo.

El último conjunto que incluimos en este estudio proviene de Cerro Lutz. Este sitio fue utilizado en distintos momentos y con intensidades diferentes según el sector, cuya consecuencia fue la formación de un complejo depósito de gran extensión. En uno de los sectores excavados se identificaron al menos dos ocupaciones diferentes. La primera de ellas representa uno o varios campamentos base, que corresponden a la unidad arqueológica GCL ya señalada anteriormente para el sitio La Bellaca 1. Los fechados en este sector arrojaron edades entre $953 \pm$ 47 (AA103648) y $916 \pm 42$ años ${ }^{14} \mathrm{C}$ AP (AA77312). Por encima de este nivel se efectuaron numerosas inhumaciones datadas entre $795 \pm 42$ (AA77311) y $730 \pm 70$ años ${ }^{14} \mathrm{C}$ AP $(\mathrm{LP}-1711)^{9}$. Entre ambos niveles se presenta una densa y compacta capa de valvas desarticuladas que en promedio tiene una potencia de 25 a $30 \mathrm{~cm}$, pero que puede engrosarse hasta alcanzar los $50 \mathrm{~cm}$ de potencia, si bien de una manera menos densa. Este engrosamiento parece ser en parte producto de la redistribución de las valvas del techo del conchero producto del cavado de las fosas del nivel superior, y de la variabilidad relacionada con el proceso de descarte. En términos de área, el cochero se extiende en los $18 \mathrm{~m}^{2}$ que se excavaron en este sector. No existe un fechado directo sobre esta estructura de acumulación, cuya cronología está acotada por los fechados de los niveles inferior y superior. Todo el sedimento del sitio y el conchero mismo fue removido con cucharín y pincel y cernido de la misma manera que en Punta Canal. Las valvas se 
encontraban desarticuladas, sin que presenten evidencias de combustión. Algunas de ellas también fueron utilizadas como materia prima para confeccionar artefactos ornamentales (Buc et al. 2019 en este volumen).

La cuantificación de los restos malacológicos se efectuó mediante el cálculo del número mínimo de individuos (MNI). Para ello se contabilizaron las charnelas que presentan más del $50 \%$ de su desarrollo original. El número de charnelas así obtenido fue dividido por dos, obteniéndose un número aproximado de individuos. Cabe destacar que en Punta Canal el grado de fragmentación es muy elevado, por lo que los valores basados en el MNI pueden estar sesgados en un grado mayor que en el resto de los sitios, aspecto que evaluamos más abajo. En este sentido, la mayor parte del registro malacológico aquí se recuperó durante el tamizado del sedimento. Todos los fragmentos recuperados y asignados como D. (R.) variabilis fueron lavados, secados y posteriormente pesados en una balanza cuya precisión es \pm 5 gr. Los datos obtenidos de cada conjunto están listados en la Tabla 2.

\begin{tabular}{lccc}
\hline \multicolumn{1}{c}{ Sitio } & Punta Canal & La Bellaca 1 & Cerro Lutz \\
\hline Superficie analizada & $18 \mathrm{~m}^{2}$ & $8 \mathrm{~m}^{2}$ & $4 \mathrm{~m}^{2}$ \\
Cronología ${ }^{14}$ C AP & $900 \pm 80$ & $1110 \pm 70$ & $953 \pm 47 / 730 \pm 70^{*}$ \\
Acumulación de valvas & dispersa & dispersa + lentes & conchero \\
Peso total D. (R.) variabilis ${ }^{* *}$ & $8.48 \mathrm{~kg}$ & $6.91 \mathrm{~kg}$ & $11.52 \mathrm{~kg}$ \\
& & & \\
Taxa & $\mathrm{MNI}$ & $\mathrm{MNI}$ & $\mathrm{MNI}$ \\
D. (R.) variabilis & 69 & 296 & 471 \\
Erodona mactroides & 1 & 11 & 2 \\
Chilina fluminea & 6 & 5 & \\
Asolene puelchella & 5 & 42 & \\
Pomacea cf. insularum & 3 & 7 & \\
D. parallelopipedon & 3 & 3 & \\
Heleobia sp. & 6 & & \\
Neocorbicula limosa & 1 & 3 & \\
Ampullaria sp. & & 0.67 & \\
\hline \multicolumn{1}{c}{ Dominancia (Ds) } & 0.55 & & \\
\hline
\end{tabular}

Tabla 2. Propiedades y composición taxonómica de los conjuntos malacológicos analizados. $\left(^{*}\right)$ Estas dataciones expresan los rangos cronológicos de las ocupaciones del sector el sitio donde se recuperó el conchero analizado aquí (ver descripción en el texto). ( $\left.{ }^{* *}\right)$ Los pesos corresponden a los exoesqueletos limpios y secos.

Diversidad en los conjuntos arqueomalacológicos

En los tres sitios D. (R.) variabilis es la especie dominante, con una escasa presencia de otras especies. En Punta Canal, estos otros taxa son de tamaño pequeño (excepto Pomacea cf. insularum y D. parallelopipedon; ver Figura 5), cuya cantidad no es significativa. La presencia de otros bivalvos podría ser producto de su inclusión en los bancos de $D$. (R.) variabilis y el transporte al sitio sin una selección taxonómica exhaustiva. Los gasterópodos, cuyos exoesqueletos se 
encuentran generalmente íntegros, pudieron haberse incorporado por causa etoecológicas al depósito arqueológico. Debido a la presencia de estas otras especies, la diversidad formal del conjunto malacológico de Punta Canal es intermedia (Ds 0,45) (Figura 6).

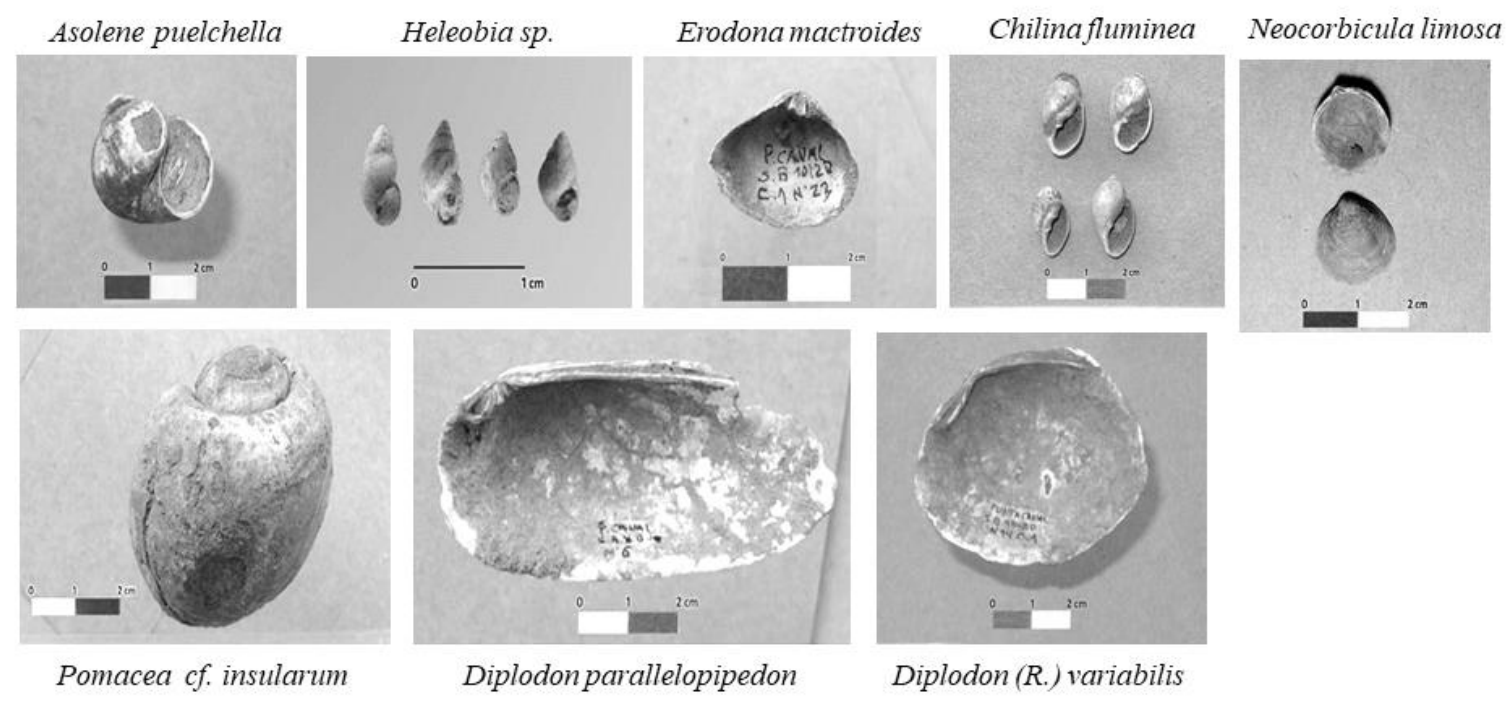

Figura 5. Ejemplares arqueológicos de las especies recuperadas en Punta Canal.

En La Bellaca sitio 1 también se observa cierta diversidad taxonómica, pero dada la mayor proporción de $D$. (R.) variabilis, la diversidad aquí disminuye ligeramente (Ds 0,33 ) respecto a Punta Canal. Las otras especies que se destacan son A. puelchella y Erodona mactroides; esta última es una especie típica de ambientes estuariales. Existen bancos de E. mactroides en diferentes puntos del paisaje del humedal del Paraná inferior, que se formaron durante la ingresión del Holoceno medio (Cavallotto et al. 2004). Si bien no puede descartarse que hayan sido objeto de recolección en bancos ubicados en el estuario del Río de la Plata, es más probable que su presencia se relacione con los procesos de erosión y redepositación fluvial que sufren los bancos subfósiles generados durante el avance del frente salino del Holoceno medio. Por otro lado, la fracción edible de E. mactroides, un micromolusco que alcanza regularmente $\sim 2,5 \mathrm{~cm}$ de talla, es muy pequeña respecto a aquellas especies que muestran evidencias claras de explotación.

En Cerro Lutz, el conjunto malacológico es monoespecífico (Tabla 2), y por ello la diversidad es sustancialmente menor (Figura 6). Su composición denota la explotación sistemática de uno o varios bancos de $D$. (R.) variabilis en un plazo acotado, que no permitió la formación de suelo ni sucesos de estratificación. 


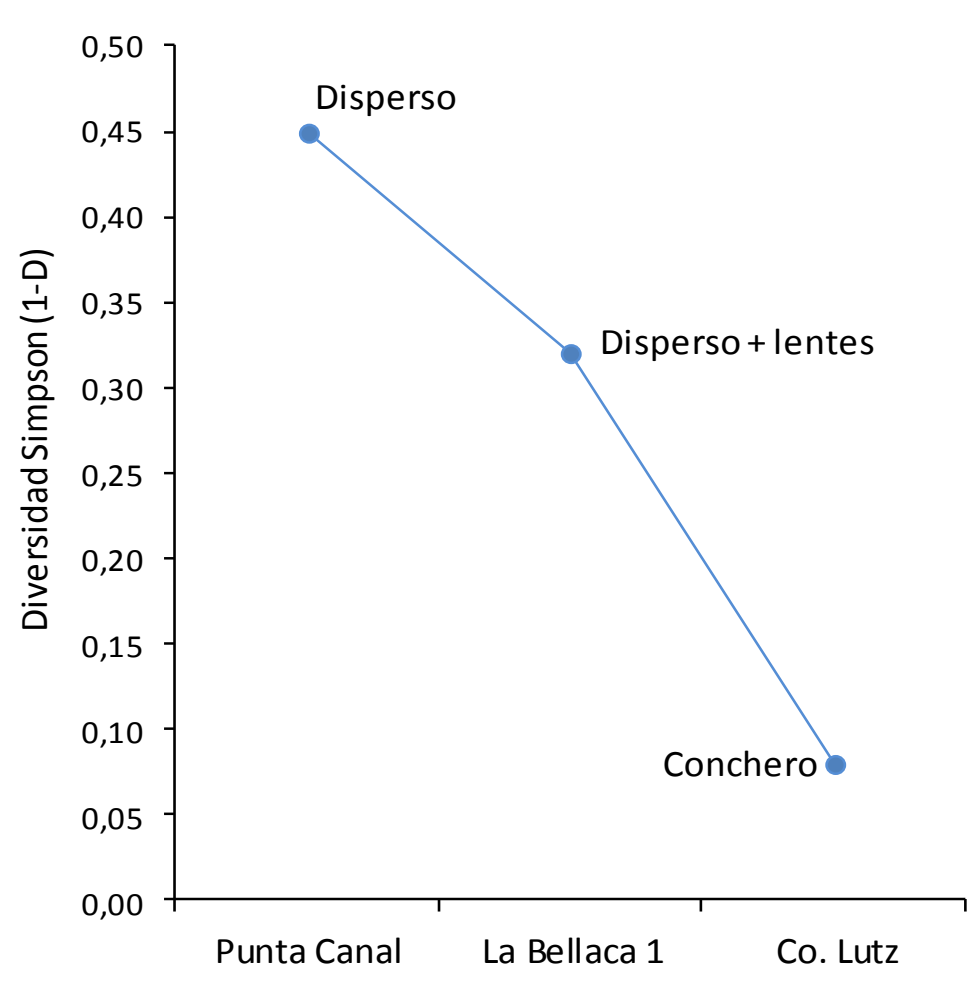

Figura 6. Diversidad (1-Ds) de los conjuntos malacológicos y formas de acumulación que adquieren las valvas en los tres sitios analizados.

Tallas en los conjuntos arqueomalacológicos

A efectos de evaluar la selectividad dimensional presente en los conjuntos arqueológicos, se midieron las tallas o alturas expresadas como la distancia entre el borde externo de la estructura umbonal y el borde externo opuesto de la valva de los ejemplares recuperados (Figura 7). Las medidas fueron tomadas por un solo operador con un calibre digital, cuya precisión es $\pm 0,1 \mathrm{~cm}$. Los resultados se compararon con las frecuencias de las tallas obtenidas en los individuos de BN1 (ver Tabla 3).

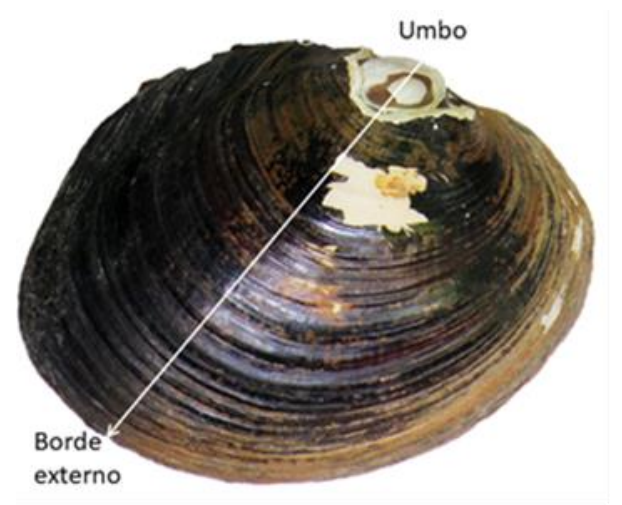

Figura 7. Altura umbonal - borde de valva. Imagen tomada y modificada de http://www.pybio.org/wp-content/uploads/2009/11/pb200166a.jpg. 


\begin{tabular}{lcccccccc}
\hline \multicolumn{1}{c}{ Sitios } & \multicolumn{2}{c}{ BN1 } & \multicolumn{2}{c}{ Punta Canal } & \multicolumn{2}{c}{ La Bellaca 1 } & \multicolumn{2}{c}{ Cerro Lutz } \\
Tamaños $(\mathrm{mm})$ & $\mathrm{N}$ & $\%$ & $\mathrm{~N}$ & $\%$ & $\mathrm{~N}$ & $\%$ & $\mathrm{~N}$ & $\%$ \\
\hline $0.1-10$ & 1 & 0 & 0 & 0 & 0 & 0 & 0 & 0 \\
$10.1-20$ & 2 & 1 & 0 & 0 & 0 & 0 & 0 & 0 \\
$20.1-30$ & 10 & 3 & 0 & 0 & 0 & 0 & 0 & 0 \\
$30.1-40$ & 42 & 13 & 0 & 0 & 5 & 18 & 0 & 0 \\
$40.1-50$ & 74 & 22 & 22 & 38 & 19 & 68 & 0 & 0 \\
$50.1-60$ & 29 & 9 & 12 & 21 & 4 & 14 & 0 & 0 \\
$60.1-70$ & 16 & 5 & 9 & 16 & 0 & 0 & 34 & 20 \\
$70.1-80$ & 30 & 9 & 10 & 17 & 0 & 0 & 83 & 49 \\
$80.1-90$ & 99 & 30 & 5 & 9 & 0 & 0 & 23 & 13 \\
$90.1-100$ & 30 & 9 & 0 & 0 & 0 & 0 & 31 & 18 \\
Totales & 333 & 100 & 58 & 100 & 28 & 100 & 171 & 100 \\
\hline
\end{tabular}

Tabla 3. Frecuencias de las tallas según la altura de las valvas de $D$. (R.) variabilis en el banco natural BN1 y en las colecciones arqueológicas.

Como se observa en la Tabla 3, el banco natural (BN1) tiene una distribución bimodal, con picos de frecuencia en individuos ubicados entre los intervalos 40.1 y 50 mm y entre 80,1 y $90 \mathrm{~mm}$. Esta distribución parece corresponderse con la presencia de una cohorte juvenil y otra adulta. En los conjuntos arqueológicos, la distribución de tallas tampoco es homogénea. En Punta Canal se observa una distribución bimodal, semejante a la frecuencia del modelo natural de BN1, pero con una absoluta ausencia de individuos menores a $40 \mathrm{~mm}$ y una representación más baja de la cohorte de adultos de mayor tamaño. Esto podría ser un reflejo de actividades de extracción en bancos previamente explotados, donde los individuos adultos se encuentran en menor proporción, como así también bancos que presentan naturalmente una escasa cantidad de individuos en las cohortes de mayor tamaño. En el conjunto de La Bellaca sitio 1 se observa una distribución unimodal, donde la concentración de tallas se ubica en los ejemplares que se encuentran entre 30,1 y $60 \mathrm{~mm}$, que corresponde a las cohortes más representada en Punta Canal, con la diferencia que en La Bellaca 1 no hay ejemplares de tamaños mayores. Esta ausencia podría deberse a actividades de extracción en bancos intensamente explotados o la recolección en bancos conformados por individuos juveniles. Finalmente, en Cerro Lutz la distribución de tallas también es unimodal, pero aquí los rangos dimensionales más representados se encuentra en el intervalo 60,1 - $100 \mathrm{~mm}$, lo que señala una alta selectividad por los ejemplares de mayor tamaño de la especie (ver Figura 8). En los tres conjuntos arqueológicos se observa una exclusión sistemática de los ejemplares más pequeños, estableciendo un umbral inferior de recolección que se ubica entre los 3 y $4 \mathrm{~cm}$ de talla. Por otro lado, en aquellos conjuntos que presentan acumulaciones más o menos concentradas como en LBS1 y Cerro Lutz (lentes y conchero respectivamente), la selectividad dimensional es más marcada que en las formas dispersas de acumulación, tal como se observa en Punta Canal. 


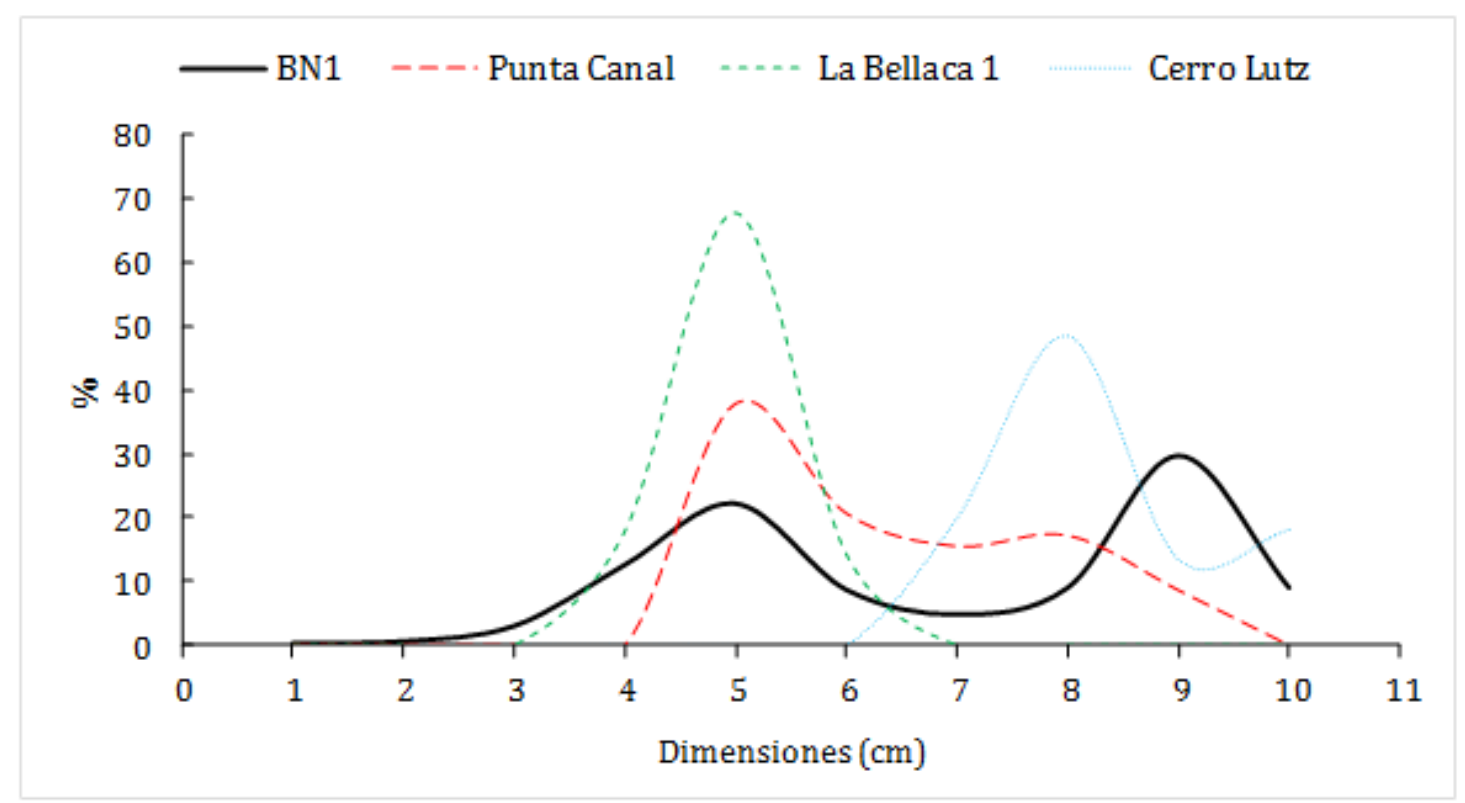

Figura 8. Distribución de tallas (umbo - borde de valva) de D. (R.) variabilis en el banco natural BN1 y en los tres sitios analizados.

\section{Contribución efectiva a la dieta}

Para estimar la cantidad de alimento asociado con el registro de las valvas en las colecciones arqueológicas, se pesaron todos los fragmentos de exoesqueletos identificados como $D$. (R.) variabilis y se aplicó la ecuación y $=0,2719 x+0,8097$ obtenida en el gráfico 2.2 de la Figura 2. También utilizamos la relación porcentual entre el peso del exoesqueleto y el tejido blando asociado de $34,6 \%$ para efectuar la estimación de masa edible. Finalmente, se estimó esta fracción en base al MNI tradicional (número de charnelas / 2), multiplicando el MNI resultante por el promedio de tejido blando obtenido en BN1 (ver Tabla 1). Luego parametrizamos estos tres resultados por unidad de volumen analizado de cada sitio, a efectos de hacer comparables los valores obtenidos (Tabla 4).

\begin{tabular}{|c|c|c|c|}
\hline & Cerro Lutz & La Bellaca 1 & Punta Canal \\
\hline Peso exoesqueletos recuperados (en kg.) & 11.52 & 6.91 & 8.48 \\
\hline Porción edible total (cálculo alométrico, en kg.) & 3.94 & 2.69 & 3.12 \\
\hline Porción edible total (calculo porcentual, en kg.) & 3.99 & 2.39 & 2.93 \\
\hline Porción edible (calculo basado en MNI, en kg.) & 3.82 & 2.40 & 0.56 \\
\hline Porción edible estandarizado (alométrico, en $\mathrm{kg} / \mathrm{m}^{3}$ ) & 3.28 & 0.75 & 0.58 \\
\hline Porción edible estandarizado (porcentual, en $\mathrm{kg} / \mathrm{m}^{3}$ ) & 3.32 & 0.66 & 0.54 \\
\hline Porción edible estandarizado (MNI, en $\mathrm{kg} / \mathrm{m}^{3}$ ) & 3.18 & 0.67 & 0.10 \\
\hline
\end{tabular}

Tabla 4. Fracciones estimadas de tejido blando de $D$. (R.) variabilis en los conjuntos arqueomalacológicos analizados. 
Las cantidades de tejido blando disponible para el consumo en Cerro Lutz y La Bellaca sitio 1 obtenidos por los tres métodos (alométrico, porcentual y MNI), arrojan valores semejantes. En Punta Canal la estimación basada en el MNI es muy diferente a la obtenida por los otros dos métodos, debido a la mayor fragmentación de las valvas que impide un cálculo adecuado de la cantidad de individuos presentes; esto resalta la importancia de utilizar diferentes aproximaciones para cuantificar el registro y contrastar los resultados, especialmente si los conjuntos están altamente fragmentados. A nivel intersitio, el conchero de Cerro Lutz posee un aporte por unidad de volumen muy superior a los restantes, derivado de la mayor densidad del registro. Si bien se debe considerar que se está comparando el cuerpo de un conchero contra perfiles completos de sitios que tienen pequeños lentes y valvas dispersas.

En términos de aporte a la dieta global, la contribución de los moluscos parece ser pequeña, si bien la incidencia de los mismos es más dependiente del área excavada que para otros recursos. Por otro lado, no deben descartarse episodios de ingesta off-site que pueden estar sesgando negativamente un mayor consumo que el observado en los sitios.

Variaciones verticales en la densidad del conchero de Cerro Lutz

En los $4 \mathrm{~m}^{2}$ que corresponden al conchero de Cerro Lutz analizado para este trabajo, las valvas comienzan a registrarse de modo significativo en el intervalo de extracción 15 20, que constituye el techo del conchero. En el intervalo de extracción 20 - 25 la densidad de valvas aumenta de manera progresiva hasta alcanzar su máximo en el intervalo 25 - 30, donde presenta la mayor compactación y densidad, cuya parametrización alcanza un valor ideal de $35 \mathrm{~kg} / \mathrm{m}^{3}$ (= 10,3 $\mathrm{kg}$ de tejido blando $\left./ \mathrm{m}^{3}\right)$. En los intervalos inferiores la presencia de valvas disminuye abruptamente (ver Figura 9). Por debajo del conchero, en la ocupación del nivel inferior del sitio, las valvas aparecen de manera esporádica, al menos dentro del sector alcanzado por la excavación.

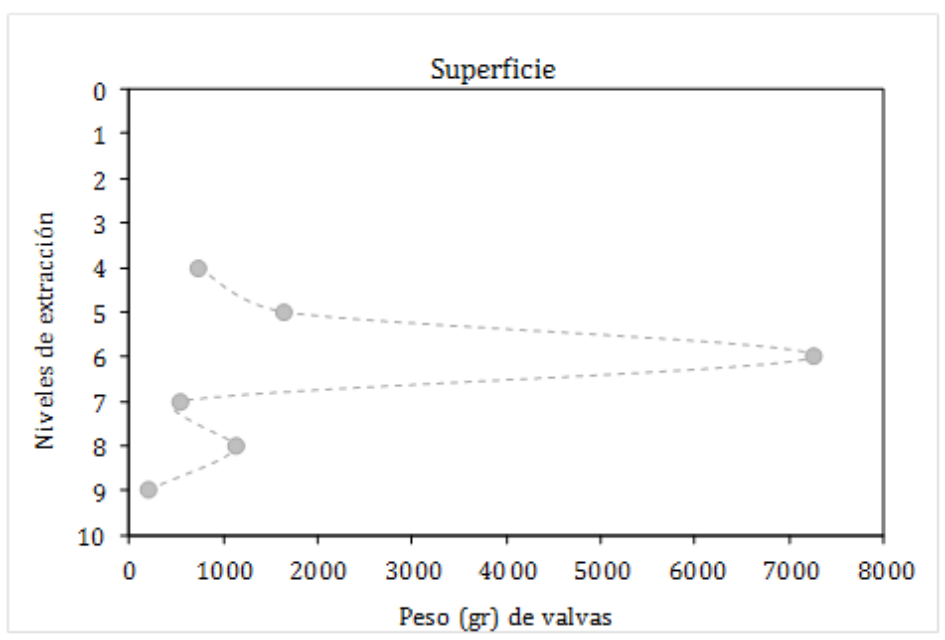

Figura 9. Distribución de las valvas en el sector analizado del conchero de Cerro Lutz. Los niveles de extracción comienzan en la superficie, y tienen una potencia de $5 \mathrm{~cm}$ cada uno. El nivel 6 representa el intervalo de extracción $25-30 \mathrm{~cm}$. 
Isótopos estables

Dentro de los estudios de la dieta de los grupos humanos del pasado, los análisis isotópicos de las presas se han integrado de una manera sistemática a la investigación arqueológica (Ambrose 1993, DeNiro 1985, 1987). Aquí incluimos un breve apartado al respecto.

Los moluscos del género Diplodon son organismos filtradores que obtienen su alimento del fitoplancton, fitobentos y de la materia orgánica existente en el plancton y en el bentos (Lara et al. 2002). En el río Paraná, las fuentes de nutrientes fluviales son básicamente $\mathrm{C}_{3}$, y por ello los organismos bénticos, infaunales y epifaunales arrojan valores empobrecidos (Marchese et al. 2014, Saigo et al. 2015). En este sentido, estudios previos efectuados en músculo de $D$. parallelopipedon arrojaron magnitudes de $\delta^{13} \mathrm{C}$ $-28,67 \pm 0,64 \%$ (Marchese et al. 2014). En el músculo ${ }^{10}$ de cinco ejemplares de D. (R.) variabilis recolectados en $\mathrm{BN} 1$, también hemos obtenido valores igualmente empobrecidos en ${ }^{13} \mathrm{C}$ (ver Tabla 5).

\begin{tabular}{llclc}
\hline \multicolumn{1}{c}{ Sitio } & \multicolumn{1}{c}{ Taxón } & Muestra & Código Lab. & $\delta^{13}{ }_{\text {músc. }}(\%)$ (V-PDB) \\
\hline San Nicolás & D. $(R$.$) variabilis$ & SN16 & AIE-25410 & -24.7 \\
San Nicolás & D. $(R$.$) variabilis$ & SN17 & AIE-25411 & -23.8 \\
San Nicolás & D. $($ R.) variabilis & SN18 & AIE-25412 & -24.0 \\
San Nicolás & D. $($ R.) variabilis & SN19 & AIE-25413 & -23.5 \\
San Nicolás & D. $($ R.) variabilis & SN20 & AIE-25414 & -24.0 \\
\hline Media & & & & -24.0 \\
Desvío & & & & 0.44 \\
CV & & & & 1.83 \\
\hline \hline
\end{tabular}

Tabla 5. Valores de $\delta^{13} \mathrm{C}$ de $D$. (R.) variabilis sobre músculo.

Para comparar estos resultados con el ecosistema del pasado, aplicamos la corrección de -0.005 \% por cada año entre 1860 y 1960, y -0.022 \%o a partir de 1960 hasta que las muestras fueron recolectadas, debido al empobrecimiento de ${ }^{13} \mathrm{C}$ en la atmósfera por las emisiones industriales (Chamberlain et al. 2005, Francey et al. 1999, Indermühle et al. 1999). Esta corrección arroja un valor promedio para D. (R.) variabilis de $-22.3 \pm 0.4 \%$ (Loponte et al. 2016b). Aún podemos hacer una segunda corrección para comparar estos resultados con el resto de las presas, cuyos valores están obtenidos en colágeno óseo. Dado que los valores en músculo están empobrecidos en relación a este último (Bond y Jones 2009, Hobson 1999, SholtoDouglas et al. 1991), aplicamos el fraccionamiento promedio observado entre ambos tejidos para el caso de los peces (Sholto-Douglas et al. 1991; con un promedio de $1.35 \%$ ). De esta manera, una señal isotópica comparable de grano grueso entre $D$. (R.) variabilis y el restos de las presas animales, ubica a este molusco en $\delta^{13} \mathrm{C}-20.95 \pm$ $0.4 \%$ (Figura 10). Esta magnitud es semejante a las presas principales de los 
cazadores-recolectores locales, que están en su gran mayoría dentro de un patrón fotosintético $C_{3}$, y por lo tanto el nivel consumo de estos moluscos no puede ser discriminado utilizando los valores de $\delta^{13} \mathrm{C}$.

No se disponen por el momento de datos de $\delta^{15} \mathrm{~N}$ como para incluirlos en un biplot con el resto de las presas. En D. parallelopipedon se obtuvieron valores de 8,60 $\pm 0,62 \%$ (Marchese et al., 2014), que son niveles semejantes a aquellos que arrojan los peces omnívoros del sistema del Paraná.

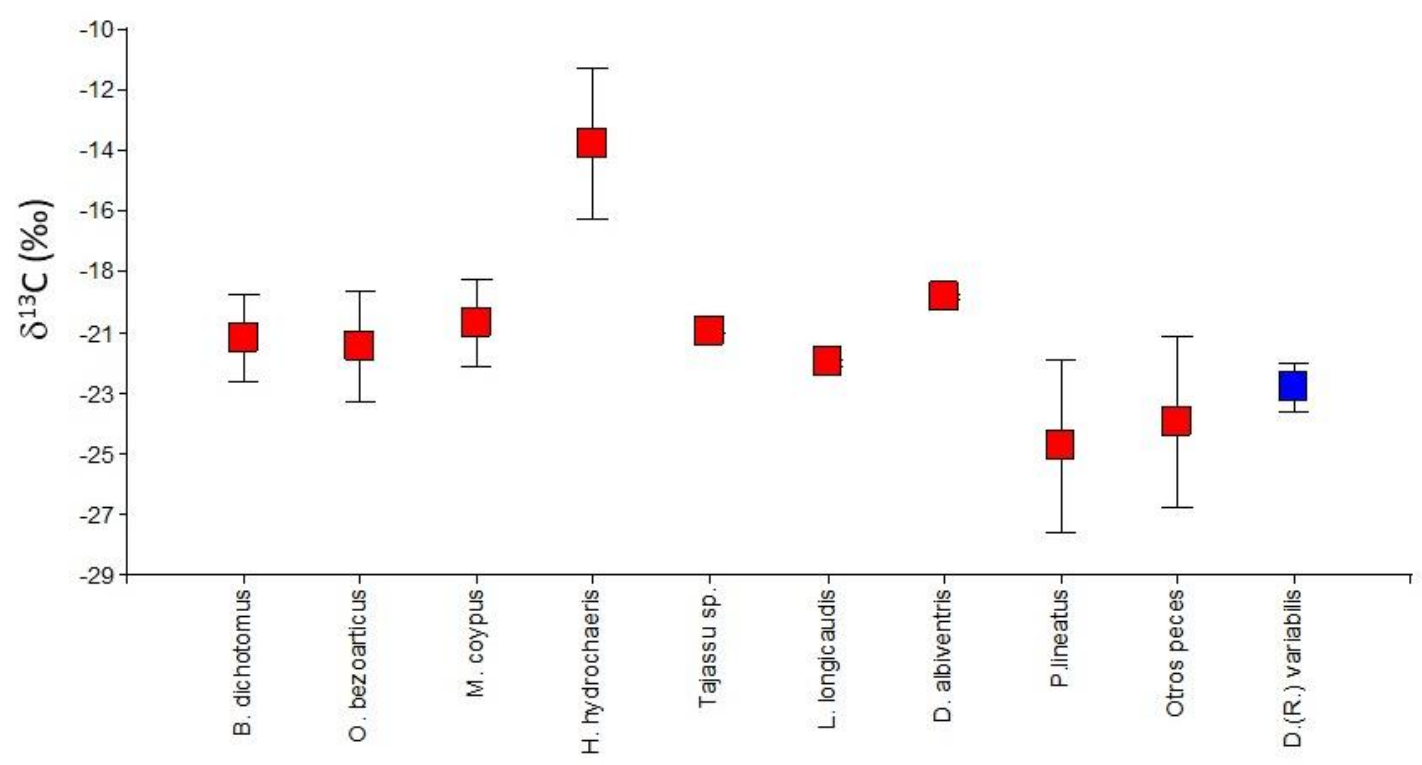

Figura 10. Valores de $\delta^{13} \mathrm{C}(\%)$ en colágeno (V-PDB) de las principales presas de los grupos cazadores-recolectores del humedal del Paraná inferior (Holoceno tardío) (tomados de Loponte et al. 2016b).

\section{Conclusiones}

La explotación sistemática de moluscos entre los grupos cazadores-recolectores de la región, es una expresión más del proceso de diversificación e intensificación de las prácticas de subsistencia que se desarrollaron hacia el final del Holoceno medio en la cuenca media e inferior del río Paraná. Probablemente representan parte de las actividades de cooperación sexo-etaria en la obtención de alimentos, conductas que son sugeridas por otras propiedades del registro local (Acosta y Loponte 2013; Loponte 2008). Los loci de recolección de $D$. (R.) variabilis se encuentran distribuidos de manera más o menos homogénea en el área, lo cual proyecta ubicuidad, alta densidad y predictibilidad; a ello se suma el bajo riesgo personal para recolectarlos, y un equipo de obtención cuyo costo de manufactura y de manutención es bajo. Este conjunto de propiedades probablemente incentivó su explotación por todas las categorías sexoetarias, distribuyendo los tiempos de captura entre más individuos, y en consecuencia, aumentando aún más su ranking como presa. 
Para el acarreo a las áreas residenciales, y en especial en el caso de los ejemplares completos, la distancia a los bancos debió constituir una variable crítica; en este sentido, el uso de dispositivos de navegación pudo haber sorteado en gran parte los costos de traslado. No obstante, la baja proporción de tejido consumible en relación al peso total pudo haber incentivado dos conductas que sesgan la representación arqueológica de este recurso. La primera es el consumo off-site, y la segunda la remoción del tejido blando para su traslado en cestas o bolsas a los sitios residenciales. De manera opuesta, lentes o inclusive concheros como el de Cerro Lutz, pueden ser localizaciones específicas de consumos off-site, que no guarden necesariamente relación con los campamentos centrales detectados en esos mismos sitios.

La variabilidad en los tamaños y en la densidad de las valvas a nivel intersitio no parece responder, en principio, a un vector temporal. Depósitos que tienen una antigüedad equivalente o menor a los fechados más recientes de Cerro Lutz, como La Bellaca sitios 2 y 3, o el nivel II del sitio Isla Lechiguanas 1 (ver fechados en Buc y Loponte 2016 y Loponte y Corriale 2019) presentan un registro de valvas disperso, sin presencia de lentes extensos ni concheros. Las diferencias podrían relacionarse con situaciones de muy corto plazo y aún episódicas, como diferencias en la localización de los sitios residenciales y la conectividad fluvial con los bancos de moluscos; distintos grados de intensificación en la explotación del ambiente en rangos temporales muy acotados; variaciones de pequeña escala en las tasas de encuentro con presas más jerarquizadas; una disminución más o menos súbita de los rendimientos marginales; conductas de intensificación con alta variación de los recursos explotados; determinadas prácticas sociales y simbólicas que no tienen una expresión temporal precisa, etc. El análisis de estos y otros puntos no pueden efectuarse sin datos cuantitativos y cronológicos que incumban a una mayor cantidad de sitios que estén ubicados en los distintos sectores que integran el complejo ambiente del humedal del Paraná inferior, con toda su variabilidad ecológica y arqueológica; por otro lado, los resultados obtenidos en BN1 si bien son significativos para comprender la oferta natural de $D$. (R.) variabilis, constituyen un dato único sobre un rango de variabilidad desconocido en la composición de los bancos de moluscos locales.

Agradecimientos: Los trabajos de campo y de laboratorio fueron parcialmente financiados por el CONICET (PIPs 11220110100565 y 11220150100482) y de la Agencia Nacional de Promoción Científica y Tecnológica (PICT 2011-2035).

\section{Notas}

${ }^{1}$ Existen algunas controversias en las clasificaciones sistemáticas de los moluscos de este género (Miyahira et al. 2017, Rumi et al. 2008). Remitimos al lector interesado a estos dos trabajos y a la bibliografía allí citada. Aquí se seguirá la nomenclatura taxonómica propuesta por Rumi et al. (2008) según lo planteado en Parisi y Liotta (2010).

2 Un análisis preliminar puede verse en Parisi y Liotta (2010).

${ }^{3}$ De los diferentes índices que se utilizan para medir la diversidad, el índice de Simpson es el más adecuado para los conjuntos locales (cf. Loponte 2008). 
4 Algunos autores también señalan la incidencia de las materias primas que aportan las presas, el prestigio y otros aspectos simbólicos que pueden incrementar los rankings de determinadas especies (Alvard 1995, Smith 2004).

5 Jochim $(1976,1981)$ señaló, entre otras cosas, la proporción de tejido graso y aspectos difíciles de medir arqueológicamente como la palatabilidad, como factores que influyen en la jerarquía de las presas. Otras críticas se basan en la exclusión de los costos de búsqueda y captura, las capturas fallidas y el reparto de las presas (Bird y O'Connell 2006; ver un resumen de estas críticas en Broughton 2011). Un ranking más complejo que incluye diversos costos, puede verse en Muscio (2004).

${ }^{6}$ La Reserva Natural Estricta de Otamendi es un sector de la llanura aluvial del río Paraná poco o nada modificado por el hombre, especialmente en lo que se refiere a la proporción de aguas libres (Haene et al. 2003); lo mismo se aplica para el área de Islas Lechiguanas donde se efectuaron los muestreos de BN1.

7 Dejamos de lado aquí a las larvas e insectos que no tienen visibilidad arqueológica.

8 Esta potencia fue registrada en un sector periférico de este sitio, ya que la casi totalidad del depósito fue destruido en oportunidad de la ampliación del canal Villanueva en la década de 1990.

${ }^{9}$ Otros fechados de otros sectores del sitio pueden verse en Buc y Loponte 2016 y Buc et al. en este volumen.

10 Para la obtención de los valores isotópicos en músculo se utilizó el método descripto en Hoefs y Schidlowski (1967), y modificaciones (Ducós 2010).

\section{Bibliografía}

Acosta, A. y D. Loponte.

2013. Complejidad social y estrategias de subsistencia en las poblaciones cazadorasrecolectoras del humedal del Paraná inferior. Cuadernos del Instituto Nacional de Antropología y Pensamiento Latinoamericano, Series Especiales 1(4): 60-74.

Acosta, A., S. Escudero, M. R. Feuillet Terzaghi, D. Loponte y L. Pérez Jimeno

2010. Conectando registros: variabilidad arqueológica en la cuenca del Paraná. Mamül Mapu: pasado y presente desde la arqueología pampeana (ed. Por M. Berón, L. Luna, M. Bonomo, C. Montalvo, C. Aranda y M. Carrera Aizpitarte) Tomo II, pp. 17-28. Editorial Libros del Espinillo, Ayacucho.

Arenas, P.

2003 Etnografía y alimentación entre los Toba-Ñachilamolek y Wichí-Lhuku'tas del Chaco Central (Argentina). Edición del autor. Buenos Aires.

Alvard, M.

1995 Intraspecific prey choice by Amazonian hunters. Current Anthropology 36: 789 818.

2003 The adaptive nature of culture. Evolutionary Anthropology 12:136-149. 
Ambrose, S. H.

1993. Isotopic analysis of paleodiets: methodological and interpretive considerations. En Sandford M.K. (ed.), Investigations of Ancient Human Tissue. Chemical Analysis in Anthropology, pp. 59-130. Gordon - Breach Science Publishers, Pensylvania.

Bayham, F. E.

1979. Factor influencing the archaic patterns of animal utilization. Kiva 44: 219-235.

Bettinger, R. L., R. Malhi y H. McCarthy

1997. Central place models of acorn and mussel processing. Journal of Archaeological Science 24 (10): 887-899.

Binford, R. L.

2001. Constructing Frames of Reference. University of California press, Berkeley.

Bird, D. W. y R. Bliege Bird

1997. Contemporary shellfish gathering strategies among the Meriam of Torres Strait Islands, Australia: testing predictions of a central place foraging model. Journal of Archaeological Science 24:39-63.

2000. The ethnoarchaeology of juvenile foragers: shellfishing strategies among Meriam children. Journal of Anthropological Archaeology 19: 461-476.

Bird, D. W. y J. F. O'Connell.

2006. Behavioral Ecology and Archaeology. Journal of Archeological Research 14:143-188.

Bond, A. L. y I. L. Jones

2009. A practical introduction to stable-isotope analysis for seabird biologists: Approaches, cautions and caveats. Marine Ornithology 37:183-188

Bonetto, A. A.

1961. Acerca de la distribución geográfica de las náyades en la República Argentina. Physis, 22(63): 259-268.

Bonetto, A. A. y I. R. Wais

1995. Southern South American stream and rivers. Ecosystems of the World 22. River and Stream Ecosystems (ed. por D. W. Goodall) pp. 257-293. Elsevier, Amsterdam.

Bonetto, A. A., M. Lanza Miranda; G. A. Iglesias y A. Pravisani 1950 Las almejas productoras de nácar. Problemas relacionados con su explotación. Notas preliminares sobre su biología. Ministerio de Hacienda y Economía. Departamento General de Industria, Comercio y Abastecimiento. División de Caza, Pesca y Piscicultura; pp. 21 - 29. Santa Fé. 
Bonetto, A. A., D. H. Di Persia y D. O. Roldán

1973 Distribución de almejas (Unionacea y Mutelacea) en algunas cuencas lenticas del Paraná médio. Revista Asoiación Ciencias Naturales Litoral 4:105-127.

Broughton, J. M.

1994 Declines in mammalian foraging efficiency during the Late Holocene, San Francisco Bay, California. Journal of Anthropological Archaeology 13: 371-401.

1997 Widening diet breadth, declining foraging efficiency, and prehistoric harvest pressure: Ichthyofaunal evidence from the Emeryville Shellmound, California. Antiquity 71(274): 845-862. doi:10.1017/S0003598X0008577X.

Broughton, J. M.

1999 Resource Depression and Intensification during the Late Holocene, San Francisco Bay: Evidence from the Emeryville Shellmound Vertebrate Fauna. University of California Publications. Anthropological Records 32. Berkeley, California.

Broughton, J. M., M. D. Cannon, F. E. Bayham y D. A. Byers

2011 Prey body size and ranking in zooarchaeology: theory, empirical evidence, and applications from the Northern Great Basin. American Antiquity 76(3): 403-428.

Buc, N., D. Loponte.

2016 Bone tools reflecting animal exploitation. the case of Lama guanicoe in the lower Paraná basin. Cuadernos del Instituto Nacional de Antropología y Pensamiento Latinoamericano, Series Especiales 3(2): 23-53.

Buc, N., A. Acosta y D. Loponte.

2019 Cuentas y tembetás malacológicos de los grupos cazadores-recolectores prehispánicos del humedal del Paraná inferior. Comechingonia. En Prensa.

Bunyard, $\mathrm{P}$.

I989 Guardians of the Amazon. New Scientist 121:38-41.

Burger, O., M. Hamilton y R. Walker

2005 The prey as patch model: optimal handling of resources with diminishing returns. Journal of Archaeological Science 32: 1147-1158.

Byers, D. A., C. S. Smith y J. M. Broughton

2005 Holocene artiodactyl population histories and large game hunting in the Wyoming Basin, USA. Journal of Archaeological Science 32: 125-142.

Caggiano, M. A.

1984 Prehistoria del NE Argentino y sus vinculaciones con la República Oriental del Uruguay y Sur de Brasil. Pesquisas, Antropología 38:5-109. 
Canon, M. D.

2003 A model of central place forager prey choice and an application to faunal remains from the Mimbres Valley, New Mexico. Journal of Anthropological Archaeology 22: 1-25.

Castellanos, Z.

1960. Almejas nacaríferas de la República Argentina del genéro Diplodon (Moll.Mutélidos). Secretaria Estado Agricola y Ganaderia de la Nación. Publicación Misceláneas, 421:1-40.

1965. Contribución al estudio biológico de almejas nacaríferas del Río de la Plata. Revista Museo La Plata 8 (60): 99-147.

Cavallotto, J. L., R. Violante y G. Parker

2004. Sea-level fluctuations during the last $8600 \mathrm{yr}$ in the de la Plata River (Argentina). Quaternary International 114:155-165.

Chamberlain, C.P., J. R. Waldbauer, K. Fox-Dobbs et al.

2005. Pleistocene to recent dietary shifts in California condors. Proc. Natl. Acad. Sci. 12 (46):16707-16711.

Chiri, O.

1972. Acerca de la utilización de valvas de moluscos y la formación de montículos de valvas en yacimientos arqueológicos del Nordeste Argentino. Relaciones de la Sociedad Argentina de Antropología VI:163-191.

Claassen, C.

1998. Shells. Cambridge University Press, Cambridge.

2000. Quantifying shell: comments on Mason, Peterson, and Tiffany. American Antiquity 65 (2): 415-418

Codding, B. F., A. R. Whitaker, and D. W. Bird.

2014. Global patterns in the exploitation of shellfish. Journal of Island and Coastal Archaeology 9(2):145-149. doi:10.1080/15564894.2014.881939.

DeNiro, M. J.

1985 Postmortem preservation and alteration of in vivo bone collagen isotope ratios in relation to paleodietary reconstruction. Nature 317: 806-809.

1987 Stable isotopes and archaeology. American Scientist 75:182-191.

Ducós, E.

2010 Informe 20100309. CONICET-INGEIS. Ms.

Francey, R. J., Allison, C. E., Etheridge, D.M., et al.

1999 A 1000 year record of $\delta 13 C$ in atmospheric CO2. Tellus 51: 170-193. 
Giovas, C. M.

2009 The shell game: analytic problems in archaeological mollusc quantification. Journal of Archaeological Science 36: 1557-1564.

González, A. R.

1947 Investigaciones arqueológicas en las nacientes del Paraná-Pavón. Publicaciones del Instituto de Arqueología, Lingüística y Folklore Dr. Pablo Cabrera, XVII Universidad Nacional de Córdoba. Córdoba.

del Barco Centenera, M.

1900. La Argentina. Colección de documentos relativos la Historia Antigua y Moderna de la Provincias Unidas del Río de la Plata. Colección Pedro de Angelis, Tomo 2.

Greslebin, H.

1931. La estructura de los túmulos indígenas del Departamento de Gualeguaychú, provincia de Entre Ríos, Argentina. Revista de la Sociedad Amigos de Arqueología del Uruguay: 5-51.

Haene, E., V. De Francesco, C. Ostrosky y A. Di Giacomo

2003 La Reserva Natural Otamendi. Descripción general. Fauna de Otamendi. Inventario de los animales vertebrados de la Reserva Natural Otamendi, Campana, Buenos Aires, Argentina. Temas de naturaleza y Conservación 3 1-192.

Hames, R. B. y W. Vickers

1982 Optimal foraging theory as a model to explain variability in Amazonian hunting. American Ethnologist 9 (2): 358-378.

Harris, M.

1979 Cultural materialism: The struggle for a science of culture. New York: Random House.

Hawkes, K., K. Hill y J. F. O'Connell

1982 Why hunters gather: Optimal foraging and the Aché of Eastern Paraguay. American Ethnologist 9:379-398.

Hill, K., H. Kaplan, K. Hawkes y A. Hurtado

1987 Foraging decisions among the Aché: New data and analysis. Ethology and Sociobiology 8:1-36.

Hobson, K. A.

1999 Tracing diets and origins of migratory birds using stable isotope techniques. Society of Canadian Ornithologists Special Publication 1:21-41. 
Hoefs, J. y M. Schidlowski

1967 Carbon isotope composition of carbonaceous matter from the Precambrian of the Witwatersrand system: Science 155: 1096-1097.

Indermühle, A., T. F. Stocker, F. Joos, F., et al.

1999 Holocene carbon-cycle dynamics based on $\mathrm{CO}_{2}$ trapped in ice at Taylor Dome, Antarctica. Nature 398:121-126.

Jochim, M.

1976 Hunter Gatherer Subsistence and Settlement: A Predictive Model. Academic Press, New York.

1981 Strategies for Survival: Cultural Behavior in an Ecological Context. Academic Press, New York.

1998 A Hunter - Gatherer Landscape. Southwest Germany in the Late Paleolithic and Mesolithic. Plenum Press, Nueva York y Londres.

Kaplan, H. S. y K. Hill

1992 The evolutionary ecology of food acquisition. Evolutionary Ecology and Human Behavior (Ed. por E. A. Smith y B. Winterhalder) pp. 167-202. Aldine de Gruyter, Hawthorne, New York.

Lara, G., A. Contreras y F. Encina

2002 La almeja de agua dulce Diplodon chilensis (bivalvia:hyriidae) potencial biofiltro para disminuir los niveles de coliformes en pozos: experimento de laboratorio. Gayana 66(2):113-118.

Lechtman, $\mathrm{H}$.

1977 Style in technology- Some early thoughts. Material Culture: Style, Organization, and Dynamics of Technology (ed. por H. Lechtman y R. Merril) pp. 3-20. West Publishing, New York.

Loponte, D.

2008 Arqueología del Humedal del Paraná Inferior (Bajíos Ribereños meridionales). Arqueología de la Cuenca del Plata. Serie Monográfica. Instituto Nacional de Antropología y Pensamiento Latinoamericano; Libros del Riel. Buenos Aires.

Loponte, D. y M. J. Corriale

2019 Patterns of resource use and isotopic niche overlap among guanaco (Lama guanicoe), pampas deer (Ozotoceros bezoarticus) and marsh deer (Blastocerus dichotomus) in the Pampas. Ecological, paleoenvironmental and archaeological implications. Environmental Archaeology. En prensa. 
Loponte, D., A. Acosta y L. Mucciolo

2012 Contribución a la Arqueología del Delta del Paraná: El nivel acerámico del sitio Isla Lechiguanas 1. Comechingonia 16:229-268.

Loponte, D., A. Acosta y P. Tchilinguirián

2016a Estructuras "monticulares", unidades arqueológicas y falsas premisas en la arqueología del noreste argentino. Anuario de Arqueología 8(8):45-78.

Loponte, D., A. Acosta y M. Corriale

2016b Isotopic trends in the diets of hunter-gatherers of the lower Paraná wetland, South America. Journal of Archaeological Science: Reports 9: 259-274.

Lothrop, S.

1932 Indians of the Paraná Delta River. Annals of the New York Academy of Sciences XXXIII: 77-232. New York.

Marchese, M. R., M. Saigo, F Zillia et al.

2014 Food webs of the Paraná River floodplain: Assessing basal sources using stable carbon and nitrogen isotopes. Limnologica 46:22-30.

Mason, R. D., M. L. Peterson y J. A. Tiffany

1998 Weighing vs. counting: measurement reliability and the California school of midden analysis. American Antiquity 63(2): 303-324.

Meehan, B.

1982 Shell Bed to Shell Midden. Canberra: Australian Institute of Aboriginal Studies.

Miyahira, I. C., S. Barbosa dos Santos y M. C. Dreher Mansur

2017 Freshwater mussels from South America: state of the art of Unionida, especially Rhipidodontini. Biota Neotropica 17(4): e20170341. http://dx.doi.org/10.1590/16760611-BN-2017-0341

Moss, M. L.

1993 Shellfish, gender, and status on the Northwest Coasts reconciling archaeological, ethnographic, and ethnohistorical records of the Tlingit. American Anthropologist 95(3):631-652.

Munro, N. D. y L. Atici

2009 Human subsistence change in the Late Pleistocene Mediterranean Basin: the status of research on faunal intensification, diversification \& specialization. Before Farming 2009 (1): 1-6. 


\section{Muscio, H. J.}

2004 Dinámica Poblacional y Evolución Durante el Período Agroalfarero Temprano en el Valle de San Antonio de los Cobres, Puna de Salta, Argentina. Tesis doctoral inédita. Facultad de Filosofía y Letras, Universidad de Buenos Aires. Buenos Aires.

Parisi, F. y J. J. Liotta

2010 Primera aproximación al consumo de moluscos Bivalvos (Diplodon sp.) en el sitio cerro Lutz, planicies Inundables del Paraná inferior. Mamül Mapu: pasado y presente desde la arqueología pampeana (ed. Por M. Berón, L. Luna, M. Bonomo, C. Montalvo, C. Aranda y M. Carrera Aizpitarte), pp. 215-226. Editorial Libros del Espinillo. Ayacucho.

Peacock, E.

2000 Assessing bias in archaeological shell assemblages. Journal of Field Archaeology 27:183-196.

Pyke, G. H., H. R. Pulliam y E. L. Charnov

1977 Optimal foraging: A selective review of theory and tests. Quarterly Review of Biology 52:137-154.

Rumi, A., D. E. Gutierrez Gregoric; V. Núñez y G. Darrigan

2008 Malacología Latinoamericana. Moluscos de agua dulce de Argentina. Revista de Biología Tropical 56 (1): 77-111.

Saigo, M., F. L. Zilli, M. R. Marchese y D. Demonte

2015 Trophic level, food chain length and omnivory in the Paraná River: a food web model approach in a floodplain river system. Ecol. Res. http://dx.doi.org/10.1007/s11284-015-1283-1

Schmitt, D.N. y K. D. Lupo.

1995 On mammalian taphonomy, taxonomic diversity, and measuring subsistence data in zooarchaeology. American Antiquity 60 (3):496-514.

Sholto-Douglas, A. D, J G. Field, y N. J. Van der Merwe $1991{ }^{13} \mathrm{C} /{ }^{12} \mathrm{C}$ and ${ }^{15} \mathrm{~N} /{ }^{14} \mathrm{~N}$ isotope ratios in the Southern Benguela Ecosystem: indicators of food web relationships among different size-classes of plankton and pelagic fish; differences between fish muscle and bone collagen tissues. Mar. Ecol. Prog. Ser. 78:23-31.

Smith, E. A.

1991 Inujjuamiut Foraging Strategies: Evolutionary Ecology of an Arctic Hunting Economy. Aldine De Gruyter, Nueva York.

2004 Why do good hunters have higher reproductive success? Human Nature 15:343 364. 
Stephens, D. W. y J. R. Krebs

1986 Foraging Theory. Oxford University Press, Oxford.

Stiner, M. y N. D. Munro

2002 Approaches to Prehistoric Diet Breadth, Demography, and Prey Ranking Systems in Time and Space. Journal of Archaeological Method and Theory 9(2):181-214.

Stiner, M. C., N. D. Munro y T. A. Surovell

2000. The tortoise and the hare: Small game use, the Broad Spectrum Revolution, and Paleolithic demography. Current Anthropology 41: 39-73.

Torres, L. M.

1911 Los Primitivos Habitantes del Delta del Paraná. Universidad Nacional de La PlataBiblioteca Centenaria, La Plata.

Torres, S., G. Darrigran y C. Damborenea

2013 Distribución del género Diplodon (Mollusca: Bivalvia: Hyriidae) en territorio Argentino mediante el uso de Colecciones Biológicas. AUGMDOMUS 5(1):90-99.

Waguespack, N. M. y T. A. Surovell

2003 Clovis hunting strategies or how to make out on plentiful resources. American Antiquity 68:333-352. 